\title{
ANL-AFP-46
}

ANL-AFP-46

\section{ENGINEERING ANALYSIS OF MIXED CARBIDE FUELS FOR LARGE BREEDER REACTORS}

\author{
by \\ J. F. de Paz and J. T. Madell \\ Components Technology Division
}

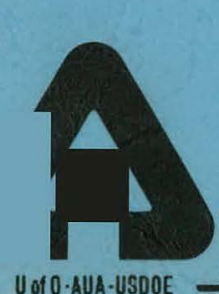

ARGONNE NATIONAL LABORATORY, ARGONNE, ILLINOIS

Prepared for the U. S. DEPARTMENT OF ENERGY

under Contract W-31-109-Eng-38 


\section{DISCLAIMER}

This report was prepared as an account of work sponsored by an agency of the United States Government. Neither the United States Government nor any agency Thereof, nor any of their employees, makes any warranty, express or implied, or assumes any legal liability or responsibility for the accuracy, completeness, or usefulness of any information, apparatus, product, or process disclosed, or represents that its use would not infringe privately owned rights. Reference herein to any specific commercial product, process, or service by trade name, trademark, manufacturer, or otherwise does not necessarily constitute or imply its endorsement, recommendation, or favoring by the United States Government or any agency thereof. The views and opinions of authors expressed herein do not necessarily state or reflect those of the United States Government or any agency thereof. 


\section{DISCLAIMER}

Portions of this document may be illegible in electronic image products. Images are produced from the best available original document. 
The facilities of Argonne National Laboratory are owned by the United States Government. Under the terms of a contract (W-31-109-Eng-38) between the U. S. Department of Energy, Argonne Universities Association and The University of Chicago, the University employs the staff and operates the Laboratory in accordance with policies and programs formulated, approved and reviewed by the Association.

\section{MEMBERS OF ARGONNE UNIVERSITIES ASSOCIATION}

The University of Arizona Carnegie-Mellon University Case Western Reserve University The University of Chicago University of Cincinnati Illinois Institute of Technology University of Illinois Indiana University Iowa State University The University of Iowa
Kansas State University The University of Kansas Loyola University Marquette University Michigan State University The University of Michigan University of Minnesota University of Missouri Northwestern University University of Notre Dame
The Ohio State University Ohio University

The Pennsylvania State University

Purdue University

Saint Louis University Southern Illinois University The University of Texas at Austin Washington University Wayne State University The University of Wisconsin

\section{NOTICE}

This report was prepared as an account of work sponsored by the United States Government. Neither the United States nor the United States Department of Energy, nor any of their employees, nor any of their contractors, subcontractors, or their employees, makes any warranty, express or implied, or assumes any legal liability or responsibility for the accuracy, completeness or usefulness of any information, apparatus, product or process disclosed, or represents that its use would not infringe privately-owned rights. Mention of commercial products, their manufacturers, or their suppliers inthis publication does notimply or connote approval or disapproval of the product by Argonne National Laboratory or the U. S. Department of Energy. 
Distribution Category: LMFBR Fuels and Materials Engineering and Development (UC-79b)

Argonne National Laboratory - 9700.South Cass Avenue Argonne, Illinois 60439

\section{ENGINEERING ANALYSIS OF MIXED CARBIDE FUELS FOR LARGE BREEDER REACHIORS}

by

J. F. de Paz and J. T. Made11

Components Technology Division

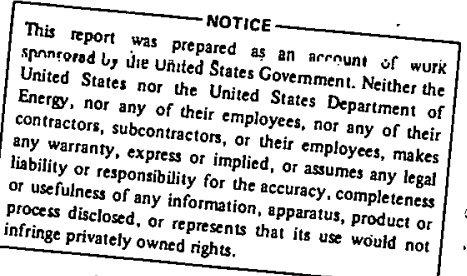

spansorod by die Uñted Stated as an arrount of wurk

Energy, nor nor the Uniled States Departmest the

contrators, ony of their employees, nor anyent of

any warranty, exprese or inplied or as

or usefulness of ansibility for the accuracy. cos any legal

infringe privated, or represents that its use product or

infing privately owned rights. 
Page

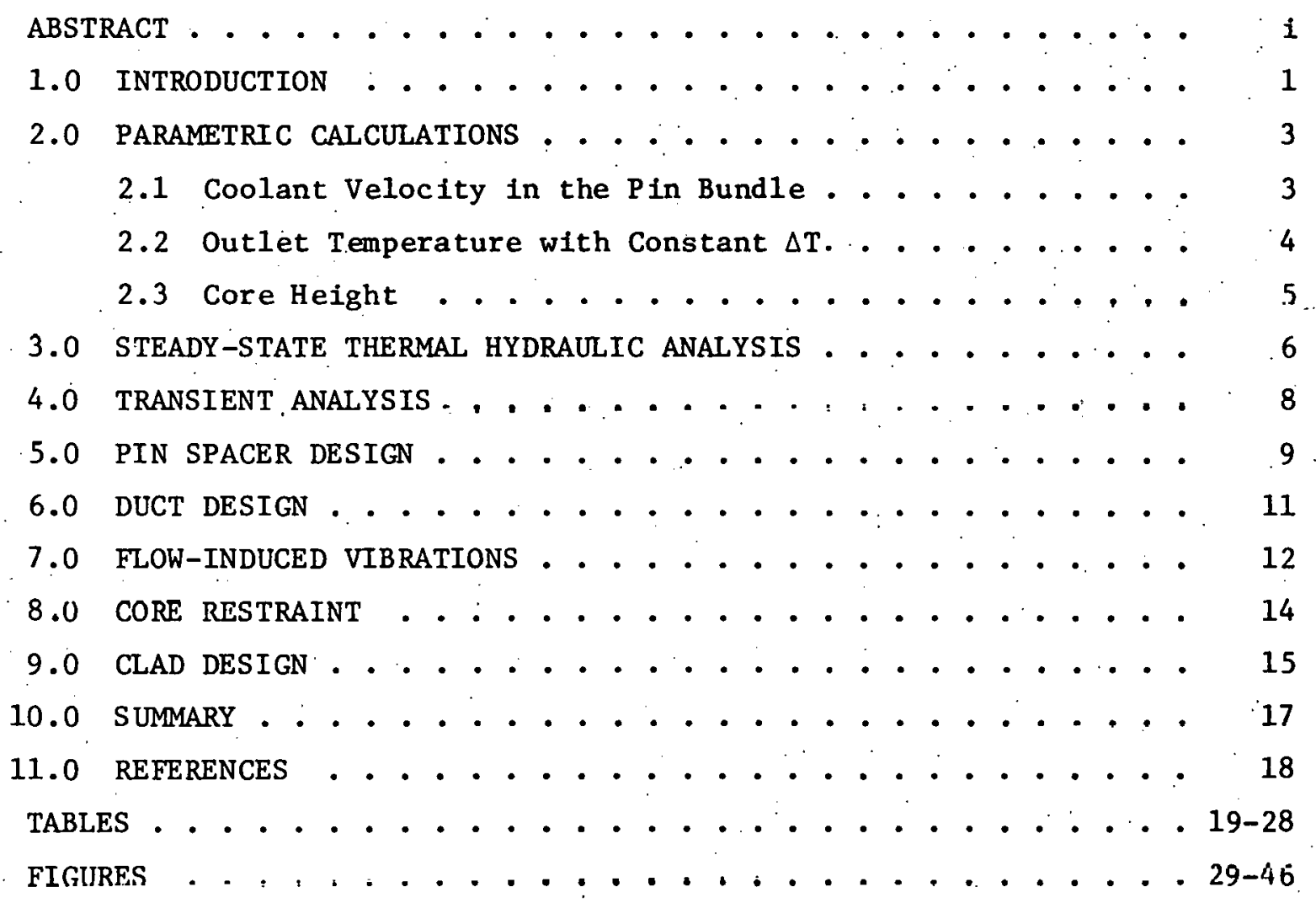




\title{
ENGINEERING ANALYSIS OF MIXED CARBIDE.
}

FUELS FOR LARGE BREEDER REACTORS

by

J. F. de Paz and J. T. Madell

\author{
ABSTRACT
}

The results of several parametric studies of the performance of sodiumbonded carbide fuel assemblies are presented. The thermal hydraulic impact of changes in coolant velocity, core height, coolant temperature rise, spacer type and duct material is considered. An evaluation of the effect of these. changes on the transient behavior, core restraint performance, flow-induced vibrations, and cladding lifetime is also given. The cladding thickness, inlet coolant temperature and spacer type are identified as the design features whose optimization appears most promising as a means of achieving an improved fuel performance. 


\subsection{INTRODUCTION}

The following is a description of the parametric design studies on sodium-bonded carbide fuel assemblies subsequent to the constrained parameter investigations of advanced fuels described in Reference 1. The work described here was aimed at investigating the effect on the subassembly performance of a relaxation of some constraints assumed in previous studies. This included parametric studies of the effect of changes in the coolant velocity core height, and core outlet temperature, as well as changes in the duct material. In addition, some aspects of the system's behavior were considered. Thus, transient thermal analysis, core restraint performance and cladding lifetime calculations were included, together with the steady state thermal hydraulic analysis and the pin spacer evaluation and flow-induced vibration calculations. The ultimate goal was to analyze the performance of the assembly components (i.e., cladding, spacers, duct, load pads, etc.) and to modify assemb1y designs or to develop new designs where those features adopted from the reference oxide program are not appropriate for an advanced fuel reactor.

The study was performed by first selecting a base design for the fuel assembly and then determining approximate operating conditions. The base case represents a design which previous analysis has shown to be near the middle of the range of attractive designs. Key parameters were then varied to cover a large part of the spectrum of attractive designs. Although the base design did not come from a complete optimization study, the study of base case and its parametric variations should be applicable to a final optimized design.

Certain design features and operating conditions are greatly influenced by neutronic considerations, e.g., fuel pin diameter and linear heat rating. Although neutronic calculations were not part of this study, key results of previous studies are presented here and factored into the selection of the base case and parameters. The general assumptions and criteria for the study are given in Table I.

The information, on which the selection of the base design of the fuel assembly was made, calle from several sources. A study of 2000 MWe, advanced fucl reactor systems, whose objective was to minimize doubling time, provided $\because$ 
the neutronic impact on the assembly design, particularly pin diameter and linear heat rating. This study also provided some constraints such as allowable pressure drop, core temperature rise and number of pins per assembly. Another source of information was the parameter design studies using the NIFD $\operatorname{code}^{2}$ which determines the pin spacings and duct dimensions from a thermal energy balance and simplified duct structural analysis.

Neutronic calculations of the 2000 MWe carbide systems were performed to obtain the doubling time for a wide range of pin diameters and linear heat ratings. The results are shown in Fig. 1 for 3 foot high, sodium-bonded carbide cores. The base design was selected to have $0.375^{\prime \prime}$ OD pins with $30 \mathrm{kw} / \mathrm{ft}$ heat rating, approximately middle values of those yiclding a minimum doubling time in the figure which roughly corresponds to a mid-value of $37 \%$ fuel fraction. 


\subsection{PARAMETRIC . CALCULATIONS}

The purpose of the parametric calculations was to understand the relationship between the coolant velocity, core outlet temperature and core height, and the design features of the sodium-bonded carbide-fueled assembly. On the basis of this understanding and of the previous neutronic studies, a base fuel assembly design and its parametric range would be chosen. The investigation was limited to determining only the global features of a fuel assembly; i.e., dimensions of fuel assembly components, material volume fractions, pressure drop and so forth. The values for material properties were taken from the previous system design studies, except those for the advanced alloys, which were obtained from Reference 3. The NIFD code (described in detail in References 1 and 2) was used for these calculations. This code computes the subassembly geometry (fuel pin pitch-to-diameter ratio, subassembly flat-to-flat distance, duct thickness and gap, etc.), bundle pressure drop, and volume fractions from the basic design assumptions. The pressure drop is calculated for both wire and grid spacers. The interassembly gap is sized so as to accommodate the duct swelling induced by irradiation, the irradiationenhanced creep, and an allowance for fuel handling proportional to the assembly flat-to-flat distance.

The results of the investigations presented here are given in terms of the fuel volume fraction for a range of linear heat ratings $(25-35 \mathrm{kw} / \mathrm{ft}$ ). These two quantities (fuel fraction and linear heat rate) give the in-reactor data needed for determining the compound system doubling time (CSDT). Thus, the resul.t.s presented here can also, be used to study qualitatively the effect of the parameters on the CSDT.

\subsection{Coolant Velocity in the Pin Bundle}

A range of coolant velocity from 25 to $40 \mathrm{ft} / \mathrm{sec}$. was studied for various pin diameters and linear heat ratings. The coolant velocity affects the fuel assembly in three areas: the required coolant flow area for a glven core $\Lambda T$, the stress and creep in the duct wall, and the axial pressure drop. From an assumed maximum head of $\sim 450 \mathrm{ft}$ for mechanical sodium pumps, a pressure drop of 60 psi is allocated the pin bundle. Changes in the primary loop configuration may allow greater pin bundle pressure drop, but subsequent studies showed that the incentive for greater pressure drop does not extst, as will be 
shown later. Figure 2 shows the calculated pressure drops for a pin diameter of $0.35^{\prime \prime}$ and the above indicated range of linear heat ratings. The lower heat rates result in higher pressure drops since they correspond to smaller flowareas for a given coolant temperature rise. It is seen that the pump requirements limit the coolant velocity to $30-35 \mathrm{ft} / \mathrm{sec}$.

An increase in the coolant velocity would tend to increase the stress levels in the subassembly duct due to the higher pressure drop. It should be noted, however, that the higher velocity allows a smaller flow area and smaller inside flat-to-flat distance and, therefore, smaller deflections in the can walls. The net result of these two effects is a decrease of the inter-subassembly gap needed for creep accommodation as the sodium velocity is increased. This is shown in.Figure 3. An outline of the algorithm used in computing these gaps is given in Section 6 . The dependence of duct stresses and thickness on bundle pressure drop and flat-to-flat distance is illustrated by Figure 4 . For low values of the pressure drop (i.e., at low coolant velocities), the effect of the flat-to-flat distance is dominant, and results in an increase of wall thickness with increasing heat rating (or bundle size). At high coolant velocities, the effect of pressure drop is dominant, and the lower heat rates, which, as shown above, result in higher friction losses, are seen to require greater duct thickness.

The combined effect of coolant flow area; inter-subassembly gap and duct thickness on the interdependence of fuel volume fraction and coolant velocity Is shown in Figure 5, in which a volume fraction increase of $\sim 7 \mathrm{v} / \mathrm{o}$ accompanies a coolant velocity increase from 25 to $40 \mathrm{ft} / \mathrm{sec}$. Increasing the coolant velocity from the constrained value of $25 \mathrm{ft} / \mathrm{sec}$, to the value corresponding to the maximum $\Delta \mathrm{P}$ results in an additional $5 \mathrm{v} / \mathrm{o}$ volume fuel fraction.

\subsection{Outlet Temperature with Constant $\Delta \mathrm{T}$}

The outlet temperature affects the subassembly performance mainly through the duct swelling. For temperatures below $\sim 1000^{\circ} \mathrm{F}$, swelling increases with temperature. Lowering the outlet temperature from $1050^{\circ} \mathrm{F}$ to $950^{\circ} \mathrm{F}$ reduces the temperature in the duct wall at the elevation of highest duct dilation from $\sim 850^{\circ} \mathrm{F}$ to $\sim 750^{\circ} \mathrm{F}$, and thus, reduces the swelling and swelling-induced creep. This effect is shown in Figure 6 for $0.35^{\prime \prime}$ and $0.40^{\prime \prime} 0$.D. pins within a 100 mil PE-16 duct. A reduction of $\sim 40$ mils in the gap swelling allowance is achieved by the $100^{\circ} \mathrm{F}$ reduction in the coolant temperature. The corresponding 
increase in the fuel volume fraction is given in Figure 7, which shows a $\sim 1.5 \mathrm{v} / \mathrm{o}$ gain over the range of linear, heat rates.

The core outlet temperature is important to many areas of the fuel assembly design, which must be investigated along with the effect on swelling to arrive at an optimum value. Specifically, its influence on the fuel element cladding strain and rupture time will be discussed later on in this report.

\subsection{Core Height}

Scoping calculations were performed to investigate the effect of varying core height on assembly performance. These included computations of pressure drop and volume fraction for core heights of $2.5,3$, and $3.5 \mathrm{ft}$. The axial blanket thickness and the radial blanket power fraction were maintained constant throughout these calculations; the power split between the core and axial blanket was taken to be proportional to the ratio of core to axial blanket volumes. Typical results are given in Figure 8 (for the fuel volume fraction) and Figure 9 (for the coolant volume fraction).

A reduction of the core height from 3 to 2.5 results in an increase of $\sim 2.8 \%$ in the fuel volume fraction for all the cases considered, whereas an. increase of the core height to $3.5 \mathrm{ft}$. reduces their volume fraction by $\sim 2.5$ points. These changes are brought about by approximately equal and opposite changes of coolant fuel volume fractions with the structural volume fraction remaining approximately constant. The core height changes have a small effect on the subassembly pressure drop. The variations encountered were smaller than the error band of the correlations used. This is due to the fact that an increase of the core height results in an increase of the pin pitch necessary to maintain the energy balance at the constant specified coolant velocity with the higher total power produced in the larger channel. This increase of the pitch partly offsets the effect on the fraction losses of the longer channel length. The findings of parametric studies and the previous neutronic studies lead to the selection of the base fuel assembly design and its parametric range, resulting in a total of 11 cases described in Table II. 


\subsection{STEADY-STATE THERMAL HYDRAULIC ANALYSIS}

The fuel and cladding temperatures were obtained by means of the THESAC Code (Reference 4). The algorithm used in it assumes azimuthal symmetry, constant. cladding conductivity and a linear dependence on temperature for the carbide fuel conductivity. Table III gives the hot channel factor used in the temperature calculations. Generally, the approach of Reference 5 has been followed, except that no wire peaking effect has been taken into consideration and that an additional subtactor has been included to account for uncertainties in the nuclear data. The wire peaking effect results from an angular assymmetry of the temperature distribution around the periphery of the fuel pin and is due to the presence of the spacer wire. When computing the fuel temperatures or circumferentially averaged cladding temperatures (as used in the cladding strain code employed in the present study), then a value of 1 must be used for the wire peaking subfactor (Reference 6), and, consequently, it has been omitted from Table III. The uncertainties in nuclear properties are estimated by Reference 6 to cause a statistical variation in the $10 \mathrm{cal}$ power density of $6.5 \%$. The integrated variation over the length of three pins delineating a subchannel is estimated by the same reference as $6 \%$. The intra-subassembly flow maldistribution subfactor is geometry dependent; its value, however, showed negligible variations for the different cases included in the parameter matrix; hence, a single value of 1.148 was used for all cases. Two values are given for the clad conductivity and thickness uncertainty: $12 \%$ for the base case and $13 \%$ for the thinner (.012") cladding. The $18 \%$ uncertainty in the gap temperature drop corresponds to a $10 \%$ uncertainty in the gap thickness (or $\pm 0.001^{\prime \prime}$ for an assumed 0.02" diametric gap) combined statistically with a $15 \%$ uncertainty in the thermal conductivity of sodium bond. A detailed discussion of the values of the other hot channel subfactors is presented in Reference 5 .

The resulting fuel and cladding temperatures are shown in Table IV. The cladding temperature appears to be most sensitive to the coolant inlet temperature while variations in the other parameters have a relatively smaller effect on the cladding. Since the cladding life is strongly dependent on temperature, as will be shown below, there appears to be considerable incentive for core designers to lower the coolant inlet temperature level. 
It is seen that the fuel temperatures for sodium-bonded carbide pins are much lower than the typical gas-bonded oxide or carbide fuels. The cladding temperature of the base design is well below current design limits $\left(\sim 1250-1350^{\circ} \mathrm{F}\right)$ : 


\subsection{TRANSIENT ANALYSIS}

The ANL reactor system transient code analyzed the sodium-bonded, carbide fueled, 2000 MWe system. The two transients under investigation were a trip from full power with minimum decay heat and a trip from $115 \%$ of full power on a flux-to-flow signal following a ramp reactivity insertion. In both transients the flow coasts down to $10 \%$ of full flow within 60 seconds. Since the important transient effects in the fuel occur within the first minute, the secondary heat transport system and steam system were not included in the transient model of the reactor.

The transients calculations were performed for the base case $\left(0.375^{\prime \prime}\right.$ pin $O D$ and $30 \mathrm{~kW} / \mathrm{ft}$ ) and for two cases which represent the extremes of thermal inertia ( $0.45^{\prime \prime}$ pin $O D$ and $25 \mathrm{~kW} / \mathrm{ft}, 0.30^{\prime \prime}$ pin $O D$ and $35^{\prime \prime} \mathrm{kW} / \mathrm{ft}$ ). The maximum temperature gradient in the coolant exiting the fuel assembly was $120^{\circ} \mathrm{F} / \mathrm{sec}$ for the base case, and $80^{\circ} \mathrm{F} / \mathrm{sec}$ and $175^{\circ} \mathrm{F} / \mathrm{sec}$ for the two extreme cases. These gradients are instantaneous values and the values over an interval of one or two seconds are much lower, approximately half of the instantaneous ones. The results show that the assembly design features do influence the transient performance and the impact of transient behavior may be an important consideration when comparing carbide and oxide cores. Il seems, however, that static thermal-hydraulic structural and neutronic considerations may be more significant to the optimized assembly design than the transient effects. 


\subsection{PIN SPACER DESIGN}

A study of the effect of bundle spacer on the subassembly pressure drop and volume fractions was conducted in order to ascertain what restraints the choice of spiral wires or grid spacers might pose on the subassembly design.: These two performance criteria are interrelated. Thus, the bundle pressure drop is significant not only in terms of pumping power, but also through its effect on the hex can stresses and bulging, and, therefore, on the subassembly volume fractions. This interdependence is influenced by the can material properties and the particular creep and swelling correlations used in the study.

The pressure drop in wire spaced subassemblies was calculated following the approach of Reference 7. For the grid spaced bundles, a semiempirical correlation developed by WARD (Reference 8) was used. Both are discussed in detail in Reference 9. Some parametric calculations of volume fraction were: also presented in Reference 9. They are extended here to advanced alloys, newer swelling and creep correlations, and a range of coolant velocities and temperatures consistent with the follow-up studies. The correlations for swelling and irradiation enhanced creep were taken from the Alloy Properties Databook (Reference 3). Typical results are presented in Figures 10 through 12 and Table V.

Figure 10 shows the effect of wire spacer type on the bundle pressure drop for 1 inear heat rates in the $25-35 \mathrm{~kW} / \mathrm{ft}$ range and pin diameters of 6.3 to 0.45 inches. It is seen that for large pin diameters and low values of the linear heat rate, both spacer concepts result in comparable pressure drops. As the linear heat rate increases (and/or the pin diameter decreases), the pressure drop in the grid-spaced subassembly becomes significantly smaller than that in the wire-spaced bundles. This trend occurs correspondingly with an increase of the pitch/diameter ratio.

The effect of the pressure drop trends on the subassembly volume fractions is shown in Figures 11 (for the fuel volume fraction) and 12 (for the structural volume fraction). The wire-spaced subassembly exhibit considerably higher structural volume fractions than the grid-spaced ones at high linear heat ratings, as the wire thickness required to give the correct pin spacing increases with heat rating. At the same time, it can be seen intuitively that, for a constant grid 
strap thickness, the grid spacer volume represents a smaller fraction of the subassembly volume as the subassembly cross-sectional area increases with increasing linear heat rating.

Table $V$ shows the gain in fuel volume fraction achieved by the use of grids with ducts of several advanced alloys. It is seen that the highest volume fraction corresponds to SS 330 , which exhibits also the highest gains when using grid spacers.

It should be noted, from the data presented above, that not only can the grid spacer result in higher fuel volume fractions, but this increase is accompanied by a larger reduction in the structural volume in the subassembly: 


\subsection{DUCT DESIGN}

The ducts of the sodium-bonded carbide fueled assemblies are hexagonally shaped structures which channel the coolant flow through the individual fuel pin bundles, and to which the other members of the assemblies are attached, such as the nozzle, shield regions, core restraint load pads and handling socket. A major mechanical loading of the duct is due to the hydraulic pressure of the coolant. The duct wall must satisfy the stress 1 imit of 0.55 a allow. It must also satisfy the criterion of limited dilation due to irradiation creep and swelling. The limit is set so that a gap between the ducts of adjacent assemblies is just sufficient for fuel handling at the end of life (typically 150-300 mils): The calculation of the duct dilation due to creep is based on beam theory. A comparison of the results from beam theory and a finite element code (AXICRP) showed excellent agreement in predicting duct dilation when beam theory was corrected for membrane stresses, planar stress/strain and stress relaxation. The corrected beam theory was used to determine the duct wall thicknesses and interassembly gaps given in Table VI, as well as the resulting fuel volume fractions. A significant increase of the fuel volume fraction appears feasible by increasing the coolant velocity or decreasing the cladding thickness.

Duct-to-duct contact has frequently been found to be the factor that determines the assembly lifetime. One means of reducing duct bulging is to use advanced alloys with low irradiation-induced creep. Some.calculations indicated that significant improvements would not be attained with the alloys considered here. Table VII shows the effect of different duct materials and fluences on the fuel volume fraction. A decrease of approximately $1 \%$ in the fuel volume fraction is observed for each $10^{23}$ nvt increment in the fluence. 


\subsection{FLOW-INDUCED VIBRATIONS}

An investigation of flow-induced vibrations of the fuel pins with the base design features was conducted over a wide range of coolant velocities. The objective was to determine the velocity value at which the vibration amplitudes are sufficiently large to produce fatigue damage. (The allowable value for the reference oxide pin is 1 min RMS).

Some preliminary calculations had been carried out previously (Reference 10) using the semi-empirical correlation prepared by $M$. Wambsganss (Reference

11). 'l'hese were extended to include the effect of an "equivalent" pin length (or distance between supports) in agreement with recent experimental data. A length of $2 \mathrm{ft}$. was adopted in this study, as opposed to $8 \mathrm{ft}$. used in a previous study. The 2 foot "equivalent" distance was selected as the most conservative distance which could be supported by both theory and experiment. The flow-induced vibration models assume a full circumferential support, whereas the wirewrap pins are only supported at one or two points on a circumference for a given elevation. The support at a specific point on the circumference is repeated at a distance equal to the wirewrap pitch. Theory would predict an "equivalent" distance for a full circumferential support to be somewhat greater than the pitch of the wirewrap. Flow-induced vibration experiments with FTRtype of fuel assemblies showed that the natural frequency corresponded to an "equivalent" distance slightly greater than the length of the wirewrap pitch. The pitch of the wirewrap for advanced fuels is expected to be in the range of 1 to 1.5 feet. To assure a degree of conservatism the value of 2 feet was, therefore, selected as the "equivalent" distance.

The maximum RMS amplitudes were then computed for a wide range of fuel design parameters using the correlation presented in Reference 1 . The effect of pin pitch to diameter ratios in the range of 1.2 to 1.4 on vibration amplitude is shown in Figure 13; the reference designs considered in the T\&H optimization studies result in $P / D$ ratios not exceeding 1.3 and are, therefore, bracketed by the data presented in the figure. The influence of pin diameters in the range of $0.3^{\prime \prime}$ to $0.45^{\prime \prime}$ is shown in Figure 14 and that of cladding thicknesses between $0.012^{\prime \prime}$ and $0.02^{\prime \prime}$ in Figure 15. Coolant velocities of 10 to 50 $\mathrm{ft} / \mathrm{sec}$ were investigated. The resulting amplitudes are seen to be smaller than $0.05 \mathrm{mils}$. Larger distances between supports were also considered, with the results given in Figure 16. The RMS amplitude is seen to increase to $\sim 0.2$ 
mils as the distance between supports increases to $4 \mathrm{ft}$. A value of $4 \mathrm{ft}$. is considered to exceed the "most conservative" equivalent distance. The values of RMS amplitude compare well with the design requirement ( 1 mil RMS) for the CRBR fuel pins.

A method to evaluate qualitatively the pin wear resulting from flowinduced vibrations is presented in Reference 12 . The propensity of the pin to wear is postulated to be dependent on temperature and a frequency-force parameter defined as: $\mathrm{PV}^{2} \mathrm{~L} / \mathrm{EID}$. Where $\mathrm{P}$ is the bundle porosity in mils per ring, $V$ the coolant velocity, $L$ the fuel pin length, E the Young's modulus: (at the axial mean temperature), I the moment of inertia of the clad and $D$ the fuel pin diameter. Following this approach, the cladding wear was investigated for various bundle clearances. It was found that, for clearances of less than 2 mils/ring no wear is predicted over the full range of design parameters. 


\subsection{CORE RESTRAINT}

In an LMFBR the radial movement of the assemblies within the core is restrained by circumferential ring(s) and/or assembly nozzle receptacles in the inlet plenum structure. Since the duct is the major structural member of the assembly, its design plays an important role in the interaction of the assemblies with each other and with the restraint system. Other assembly features, such as the fission gas plenum, and operating conditions also influence the performance of the core restraint system.

Core restraint analyses were carried out to determine the general relationships of fuel assembly features to core restraint performance. Because of its ready availability, the analysis was carried out with the temperature and flux distribution data from a 1200 MWe advanced oxide system. (The source of these data does not affect the relationships obtained from the study, so that the results are applicable to carbide reactors as well.) The configuration of a radial row (spoke) of assemblies under full power conditions is shown in Figure 17 for the base assembly design. As seen in the figure, the tops of the assemblies are displaced outwardly and the fissile regions inwardly due to the interaction of the assemblies bowed from differential thermal expansion and swelling. Changes in most assemhly features did not produce a significant changc in the interaction pattern. However, increasing the duct wall frnm 80 to $\sim 140$ mils resulted in greater assembly displacements and higher force levels among the assemblies as seen in Figure 18. An important consequence is that the alignment between a control assembly and its drive line would be much poorer with thicker ducts. 


\subsection{CLAD DESIGN}

The clad contains the fuel, its fission products, and the sodium bond. The mechanical loading on the clad consists of the fission gas pressure and the thermal gradients. through the wall. No loss of mechanical strength is assumed due to the attack of the internal clad surface. However, coolant corrosion and fabrication flaws are considered in determining the clad thickness during the assembly life.

Three criteria have been used for clad integrity. A ductility-limited strain of $\leq 0.2 \%$ for steady-state conditions ( $\leq 0.7 \%$ for all transients) was used for the FTR pin analysis. Both cumulative damage function $(\leq 1.0)$ and ductility-limited strain have been employed on the CRBRP. HEDL has proposed a total inelastic strain limit of $1-3 \%$ in the advanced oxide program. There does not seem to be sufficient information for choosing the criterion for this study so all three quantities were investigated.

Clad stress and strains were obtained with the FRST code (Reference 13). This program, in its original version, incorporates a one-dimensional algorithm to compute the steady-state and transient stresses and strains in stainless steel cladding from burnup data and fuel fission gas pressure and temperature histories. Both thermal creep and irradiation-induced effects are taken into consideration. The code was modified to extend its capability to the study of advanced alloy claddings, making use of the correlations proposed in the Alloy Properties Databook (Reference 3) for stress-free and stress-enhanced swelling, thermal and irradiation-enhanced creep, cladding corrosion, and creep rupture.

Although the code has a transient analysis capability, only steady-state conditions were considered at this time. The cladding was taken to be subject to an internal loading resulting from fission gas pressure. FRST predicted no fuel-cladding interaction for residence times of up to 1000 days. The fission gas release was computed by means of the UNCLE code (Reference 14), and FRST was then used to assess the pin lifetime for both the nominal fission gas pressure (as predicted by UNCLE) and a set of high pressure values meant to take into account the uncertainties in the current fuel behavior models.

The results for the base case and parametric variation thereof are given in. Table VIII for a residence time of 1000 days. The clad performance is presented in terms of total strain and cummulative damage funtion. The end-of-life 
cladding thickness (as affected by outside surface wear) is also given. All cases (using SS $316,20 \% \mathrm{CW}$ ) reached a lifetime of 1000 days, except that with a high inlet temperature. Table IX shows the results for a residence time of 600 days; the total strain is seen to be within safe limits for the high temperature cases. The performance of advanced alloy claddings at high pressure and for 600 and 1000 days residence times is presented in Table $\mathrm{X}$. All alloys meet the requirements with the exception of $\mathrm{HT}-9$ and of SS 330 at 1000 days. It is seen from the above that the reference designs considered here, with 40-inch plenum lengths, are not limited by cladding endurance in any significant way. In fact, since the high fission gap pressures are meant to be conservative, it appears that a shorter plenum length than that considered so far might be feasible. 


\subsection{SUMMARY}

The engineering studies presented here have shown satisfactory performance of the sodium-bonded carbide fuel assembly design in most aspects under investigation. Calculations of cladding and duct temperatures, of flow-induced vibrations, core restraint performance and clad lifetime yielded values well within the limits for the base design and its parametric variations. An area in which the performance needs improvement is the duct design. Substantial duct bulging, resulting partly from the high fluence-to-burnup ratio in carbide systems, is the factor which limits the life of the assembly.

The study also Identified promising areas for modifying the base design. Grid spacers were predicted to result in lower pressure drops and higher fuel volume fractions than were assemblies with wire-spaced. Based on the fission gas pressure from the fuel modeling code, the cladding thickness may be reduced to 12 mils, which would improve breeding while still allowing the burnup goal. Reducing the inlet temperature by $50^{\circ} \mathrm{F}$ extends the assembly life by reducing the duct bulging and the $\mathrm{CDF}$ in the cladding. 


\subsection{REFERENCES}

1. Barthold, W. P., Breeding Performance and Pin Diameter Optimization For Mixed Carbide and Nitride Fuels in 5000 MWT LMFBRS, draft.

2. Beitel, J. C., NIED Code Documentation, to be published.

3. Laidler, J. J., Alloy Properties Databook, TC-293, Rev. 1, June 1975.

4. Noxes, R. C. and Pauze, R., THESAC - A Thermal and Hydraulic Analysis. Code for Sodium Fast Reactor Survey Calculations, CEND-3467, Combustion Engineering, Inc.

5. de Paz, J. F., Engineering Hot Channel Factors for Mixed Carbide and Nitride Fuels in 5000 MuT LMFBRS, ANL-AFP-18, July 1975.

6. Carelli, M. D. and Spencer, D. R., CRBRP Assemblies Hot Channel Factors Preliminary Analysis, WARD-D-0050, Westinghouse Advanced Reactors Division, October 1974.

7. Novendstern, E. H., Turbulent Flow Pressure Drop Model for Fuel Rod Assemblies Utilizing a Helical Wire-Wrap Spacer System, Nuclear Engineering and Design, Vol. 22, 1972.

8. Schwallie, A. L., WARD, personal communication.

9. de Paz, J. F., Pressure Drop and Volume Fraction of Grid and Wire Spaced Subassemblies, ANL-AFP-13, Argonne National Laboratory, October 1975.

10. Cha, B. K., Sensitivity of Parallel Flow-Induced Vibrating in LMFBRs to Changes in Material Constants and Assembly Geometries, in preparation.

11. Wambsganss, M. W. and Chen, S. S., Tentative Design Guide for Calculating the Vibration Response of Flexible Cylindrical Elements in Axial Flow, ANL-ETD-71-07, Argonne Nationa1 Laboratory, June 1971.

12. Jacobs, D. C., An Examination of the Factors Affecting Clad Wear During Operation in LMFBK Systems, LRA-/3-484, April 1975.

13. Huba, J. J. and Schwegler, E. C. to R. M. Vijuk, WARD, LMR-74-1552, December 2, 1974 .

14. Billone, M. C. et al, UNCLE - A Computer Code to Predict the Performance of Advanced Fuels in Breeder Reactors, Trans. Aero. Nuc1. Loc., 19, 1974. 
TABLE: I GENERAL ASSUMPTIONS. AND CRITERIA

Reactor Power, MWE
Core Power, \%
Total Power Peaking
Pins/Ass'y
Axial Blanket Length (in)
Cycle Length (FPD)
Residence Time (FPD)
Max. Ass'y $\triangle P$ (psi)
Core $\triangle T$ ( ${ }^{\circ}$ )
Material Properties
Cladding Lifetime

Duct

Fuel

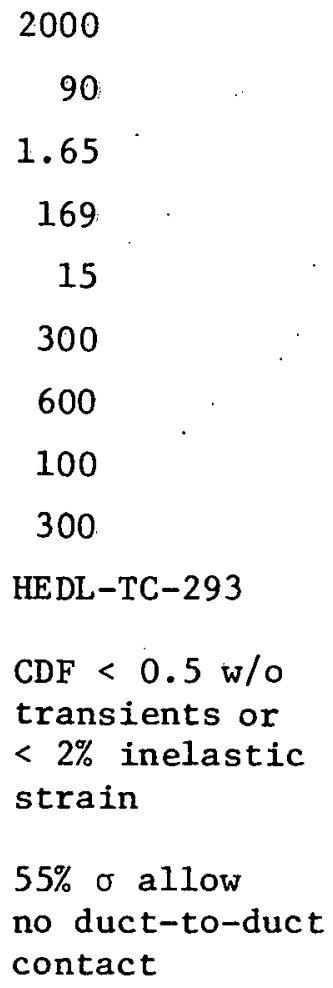


TABLE - II BASE DESIGN AND PARAMETRIC VARIATIONS

\begin{tabular}{lrc} 
Parameter & $\begin{array}{c}\text { Base } \\
\text { Case }\end{array}$ & Variation \\
\hline Pin OD (in) & .375 & $0.35,0.40$ \\
Linear Heat (kW/ft) & 30 & 35 \\
Clad. Thick (in) & .015 & .012 \\
Core Ht. (in) & 36 & 30,42 \\
Inlet Temp: ( $\left.{ }^{\circ} \mathrm{F}\right)$ & 650 & 600,700 \\
Na Velocity (Ft/Sec) & 30 & 35 \\
Grid Spacer Design & wire & grid
\end{tabular}


TABLE III ENGINEERING HOT CHANNEL SUBFACTORS

CONTRIBUTOR

\section{A. Direct}

Inlet Flow Maldist.

Intra S/A Flow Maldist.

Interchannel Mixing

Power Control Band

\section{B. Statistical}

Fissile. Fuel Maidist.

Power Measurement

Nuclear Data

Rod Diameter, Pitch \& Bow Film Coefficient

\begin{tabular}{|c|c|c|c|c|}
\hline 1.035 & 1.035 & 1.035 & 1.035 & 1.035 \\
\hline 1.087 & 1.087 & 1.087 & 1.087 & 1.087 \\
\hline 1.06 & 1.065 & 1.065 & 1.065 & 1.065 \\
\hline \multirow[t]{3}{*}{1.011} & & & & \\
\hline & 1.25 & & & \\
\hline & .. : & & & 1.16 \\
\hline . & & $\left\{\begin{array}{l}1.12 \\
1.13\end{array}\right.$ & 1.18 & \\
\hline
\end{tabular}

\begin{tabular}{|c|c|c|c|}
\hline 1.05 & 1.012 & & \\
\hline 1.148 & 1.111 & & \\
\hline 1. & & & \\
\hline 1.02 & 1.02 & 1.02 & 1.02 \\
\hline
\end{tabular}

$\therefore$ Fue1: Conductivity:

Clad Conduct. \& Thickn.

Gap Coefficient

COOLANT

FILM

CLAD

GAP

FUEL .$$
1.2
$$

(1)

(1.020

P


TABLE IV STEADY STATE FUEL AND CLADDING TEMPERATURES

Parameter

Base Case

$P$ in OD (in)

Core Height (in)

$\mathrm{T}_{\text {in }}\left({ }^{\circ} \mathrm{F}\right)$

$\Delta \mathrm{T}\left({ }^{\circ} \mathrm{F}\right)$

LHR (Kw/ft)

Clad (mils)

Velocity (Ft/Sec)
Nominal Temp.

$\left({ }^{\circ} \mathrm{F}\right)$

Values

\begin{abstract}
Values
\end{abstract}
$\mathrm{P} / \mathrm{D}$

Clad

Fue1

$1.225 \quad 1023$

1921

$1.264, \quad 1029$

1932

1912

$1.192 \quad 1018$

1925

$1.183 \quad 1028$

1920

$1.260 \quad 1022$

1876

1.221

973

1.228

107

1.248

1011

1.2691038

33

12

1.2.2. 1010

35

$\begin{array}{lll}1.186 & 1022 \quad 1920\end{array}$

1967

1908

2092

1900

Maximum Temp.

$\left({ }^{\circ} \mathrm{F}\right)$

Clad Fuel

$1160 \quad 2195$

$1171 \quad 2207$

$1151 \quad 2183$

$1180 \quad 2199$

$1158 \quad 2194$

$1110 \quad 2150$

$1210 \quad 2239$

1132 . 2180

$1186 \quad 2401$

$1143 \quad 2169$

$1158 \quad 2193$ 
TABLE V EFFECT OF SPACER TYPE ON VOLUME FRACTIONS

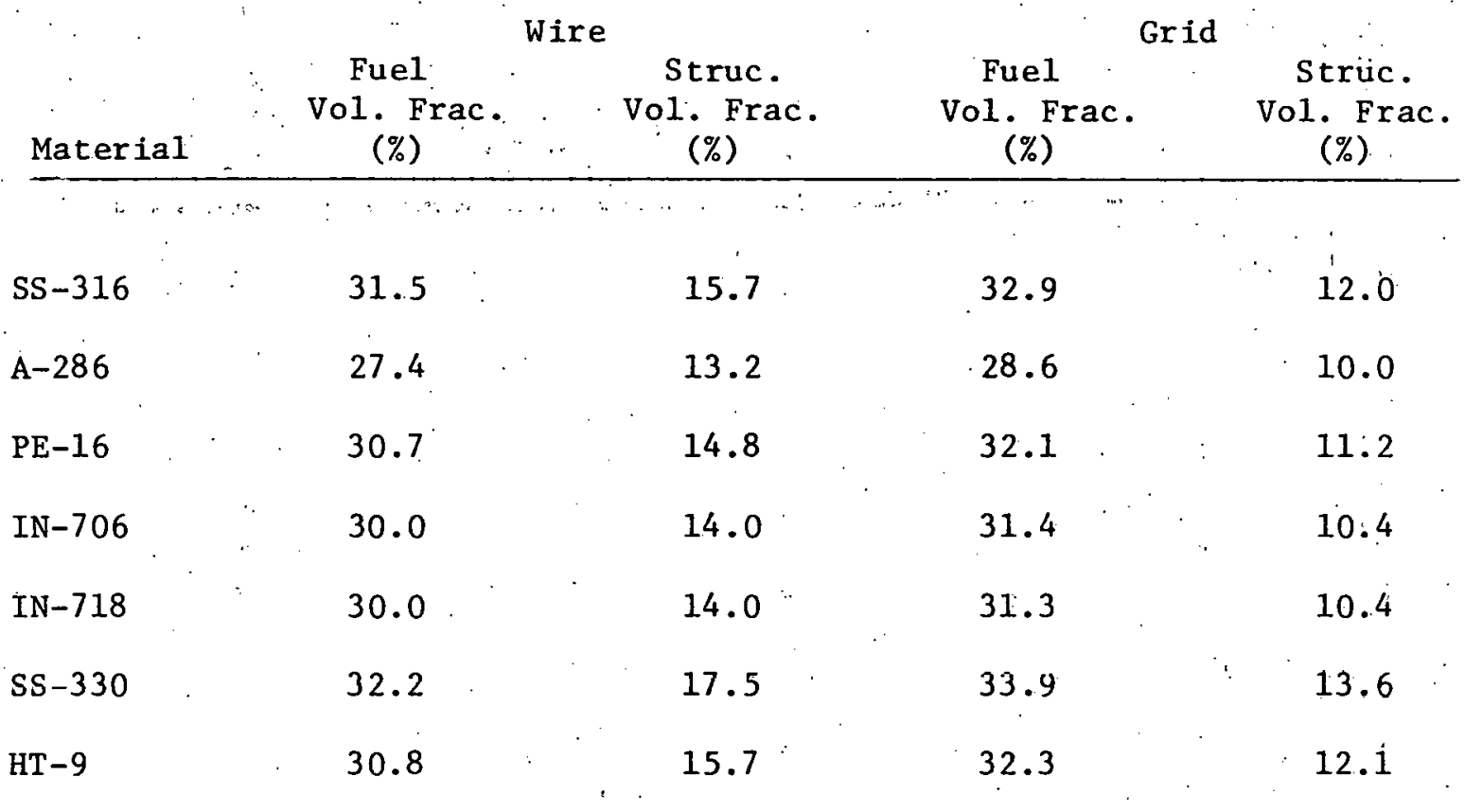

O.D. $=0.35$ in.

L.H.R. $=35 \mathrm{Kw} / \mathrm{ft}$

$\mathrm{T}_{\text {out }}=950^{\circ}$

$\mathrm{Na} V e l .=30 \mathrm{ft} / \mathrm{sec}$ 
TABLE VI EFFECT OF VARIATIONS OF THE DESIGN PARAMETERS IN THE DUCT GEOMETRY

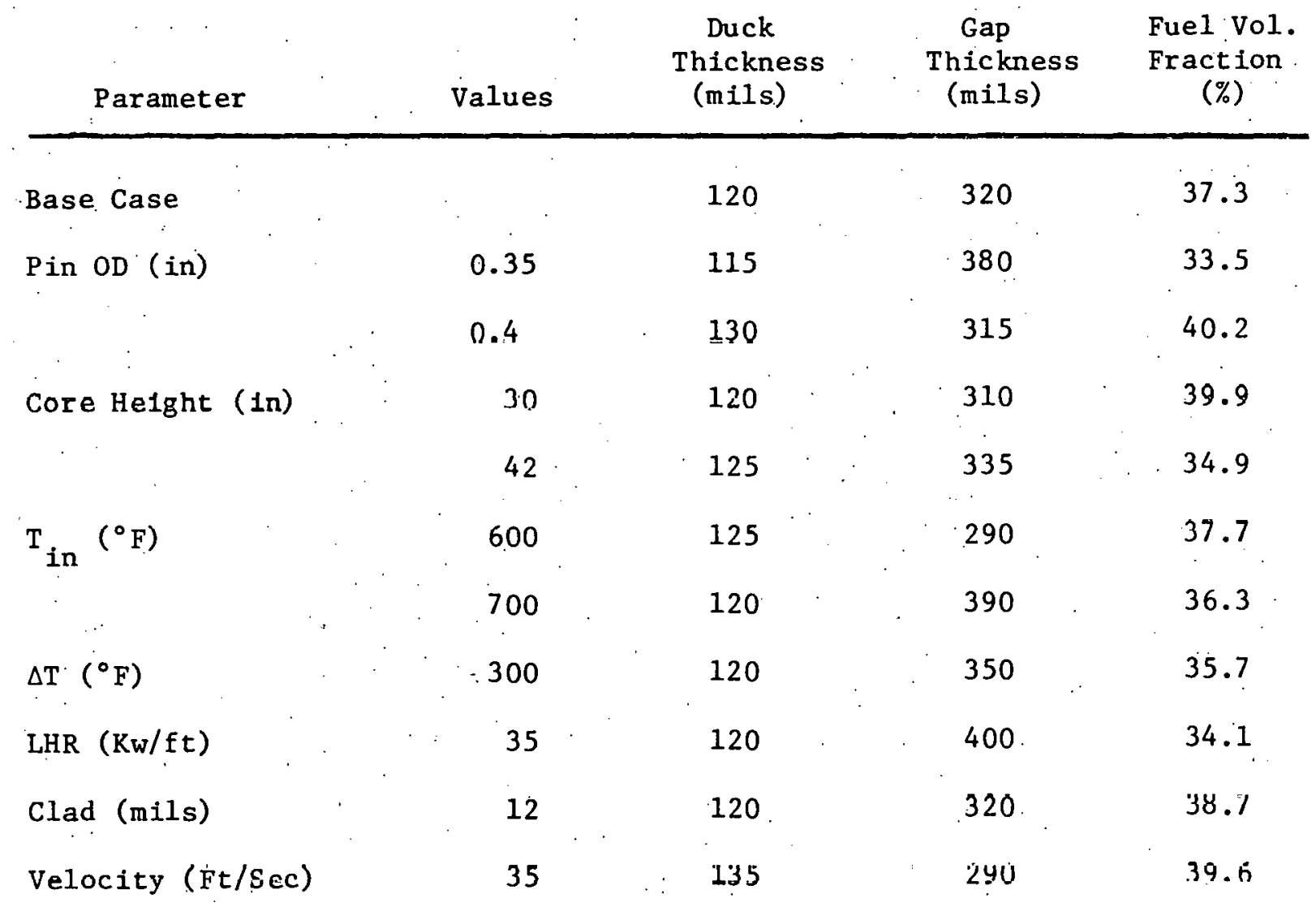


TABLE VII FUEL FRACTIONS FOR DUCTS OF VARIOUS ALLOYS AT THREE FLUENCE LEVELS

Fuel Fraction (\%)

\begin{tabular}{llcc} 
Al1oy & $1 \times 10^{23}$ & $2 \times 10^{23}$ & $3 \times 10^{23}$ \\
\hline $\begin{array}{c}\text { PE-16 } \\
\vdots\end{array}$ & 38.7 & 37.3 & 36.2 \\
$\begin{array}{c}\text { SS-330 } \\
\vdots\end{array}$ & 38.7 & 38.1 & 37.6 \\
A-286 & 37.1 & 34.5 & 32.4 \\
IN-718 & 38.8 & 37.4 & 36.3 \\
IN-706 & 38.8 & 37.4 & 36.3 \\
HT-9 & 38.6 & 37.4 & 36.3
\end{tabular}


TABLE VIII SS-316 CLAD STRUCTURAL CALCULATION FOR 1000 DAY LIFETIME AND HIGH FISSION GAS RELEASE

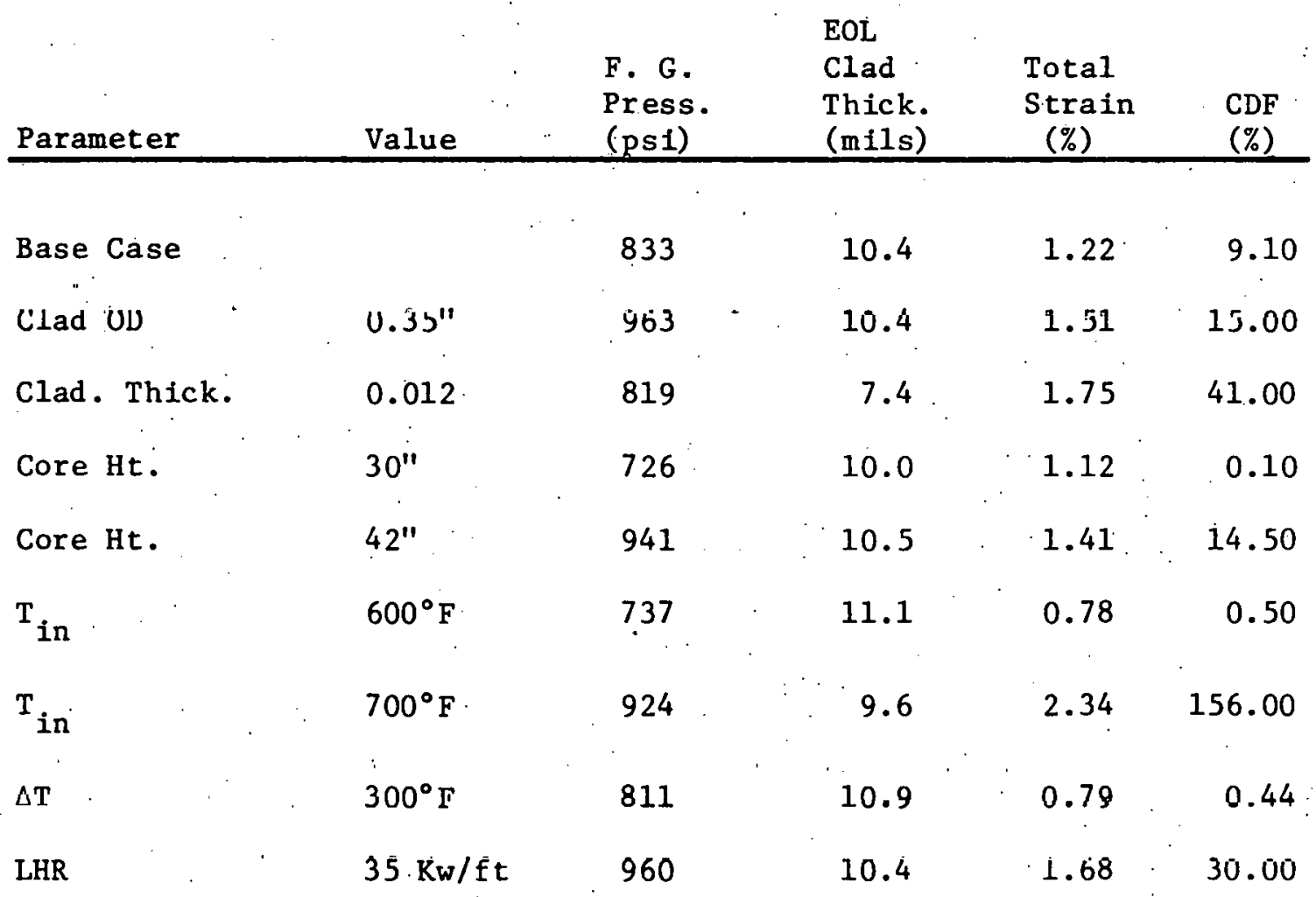


TABLE IX SS-316 LIFETIME CALCULATIONS FOR FUEL ASSEMBLY DESIGN PARAMETERS (High Press. 600 Days)

\begin{tabular}{|c|c|c|c|c|c|}
\hline Parameter & Value. & $\begin{array}{l}\text { F. G. } \\
\text { Press. } \\
\text { (psi) }\end{array}$ & $\begin{array}{l}\text { Clad } \\
\text { Thick. } \\
\text { (mils) }\end{array}$ & $\begin{array}{l}\text { Total } \\
\text { Strain } \\
(\%)\end{array}$ & $\begin{array}{l}\text { CDF } \\
(\%)\end{array}$ \\
\hline Base Case & ${ }^{\prime}$ & 460 & 12.3 & 0.33 & 0.60 \\
\hline OD & $0.35^{\prime \prime}$ & 532 & 13.2 & 0.40 & 0.70 \\
\hline OD & $0.40^{\prime \prime}$ & 407 & 12.3 & 0.29 & 0.45 \\
\hline Clad. & 0.012 & .452 & 9.3 & 0.42 & 0.60 \\
\hline Core Ht. & $42^{\prime \prime}$ & 520 & 12.3 & 0.37 & 0.55 \\
\hline Core Ht. & $30^{\prime \prime}$ & 401 & 12.0 & 0.32 & 1.25 \\
\hline $\mathrm{T}_{\underline{\text { in }}}$ & $600^{\circ} \mathrm{F}$ & 407 & 12.7 & 0.24 & 0.07 \\
\hline $\mathrm{T}_{\text {in }}$ & $700^{\circ} \mathrm{F}$ & 510 & $11: 5$ & $0: 50$ & 0.57 \\
\hline$\Delta \mathrm{T}$ & $300^{\circ} \mathrm{F}$ & 448 & 12.6 & 0.22 & 0.03 \\
\hline LHR & $35 \mathrm{kw} / \mathrm{ft}$ & 530 & 12.2 & 0.43 & 0.97 \\
\hline Velocity & $35 \mathrm{ft} / \mathrm{sec}$ & 460 & 12.3 & 0.33 & 0.53 \\
\hline
\end{tabular}


TABLE $X$ AdVANCED ALLOY CLAD LIfETIME CALCIJLATIONS FOR BASE PARAMETERS (HIGH PRESS) •

E00 DAYS (500 PSI)
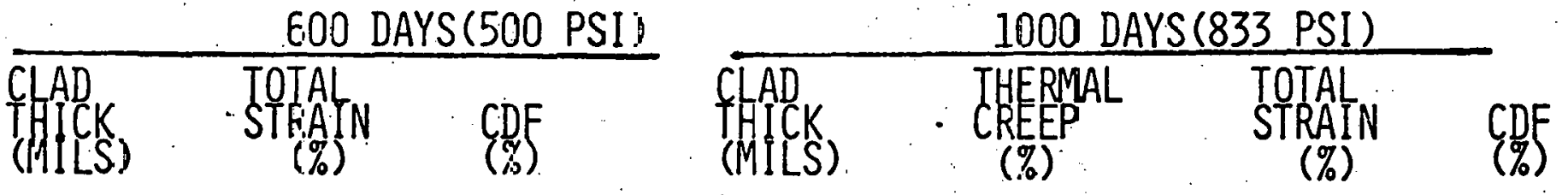

ALLOY

SS-316

12.3

0.33

0.61

10.4

0.59

1.22

9.1

PE-16

12.1

0.23

0.10

10.0

$\sim c$

0.59

0.23

$M-813$

11.5

0.23

0.15

9.2

$\sim 0$

0.62

0.30

SS-330

11.5

0.42

0.62

9.2

0.89

1.50

9.5

A-286

11.5

0.25

0.92

9.2

0.06

$0.70 \quad 1.8$

IN -718

12.9

0.22

0.28

11.4

$\sim 0$

$0.53 \quad 0.92$

IN-706

12.1

0.22

0.29

10.2

i 0

$0.56 \quad 1.0$

HT-9

10.8

0.25

62.2

8.0

2.1

$2.74>100$ 


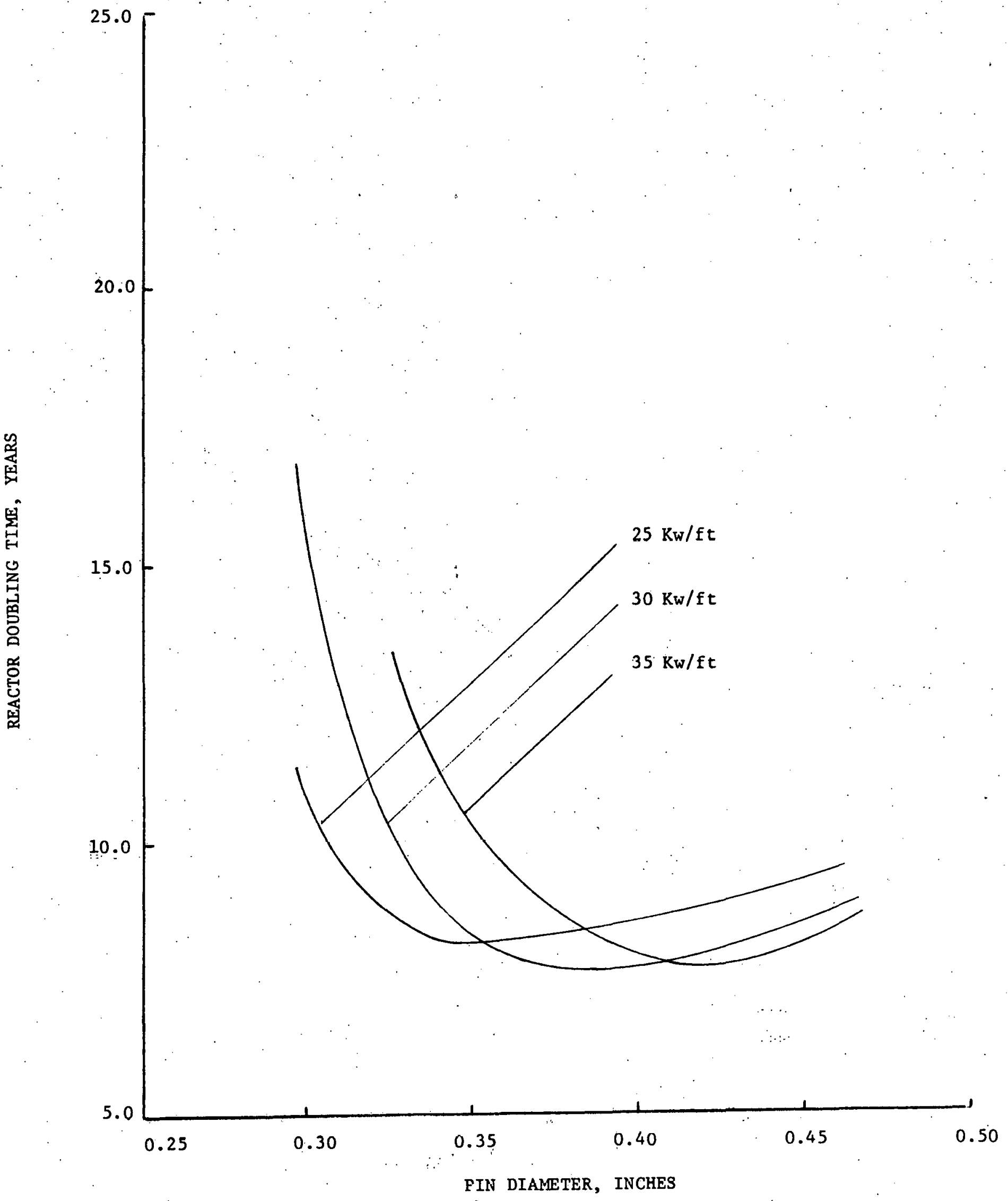

FIG. 1 EFFECT OF PIN DIAMETER ON DOUBLING TIME (FROM REF. 1 ). 


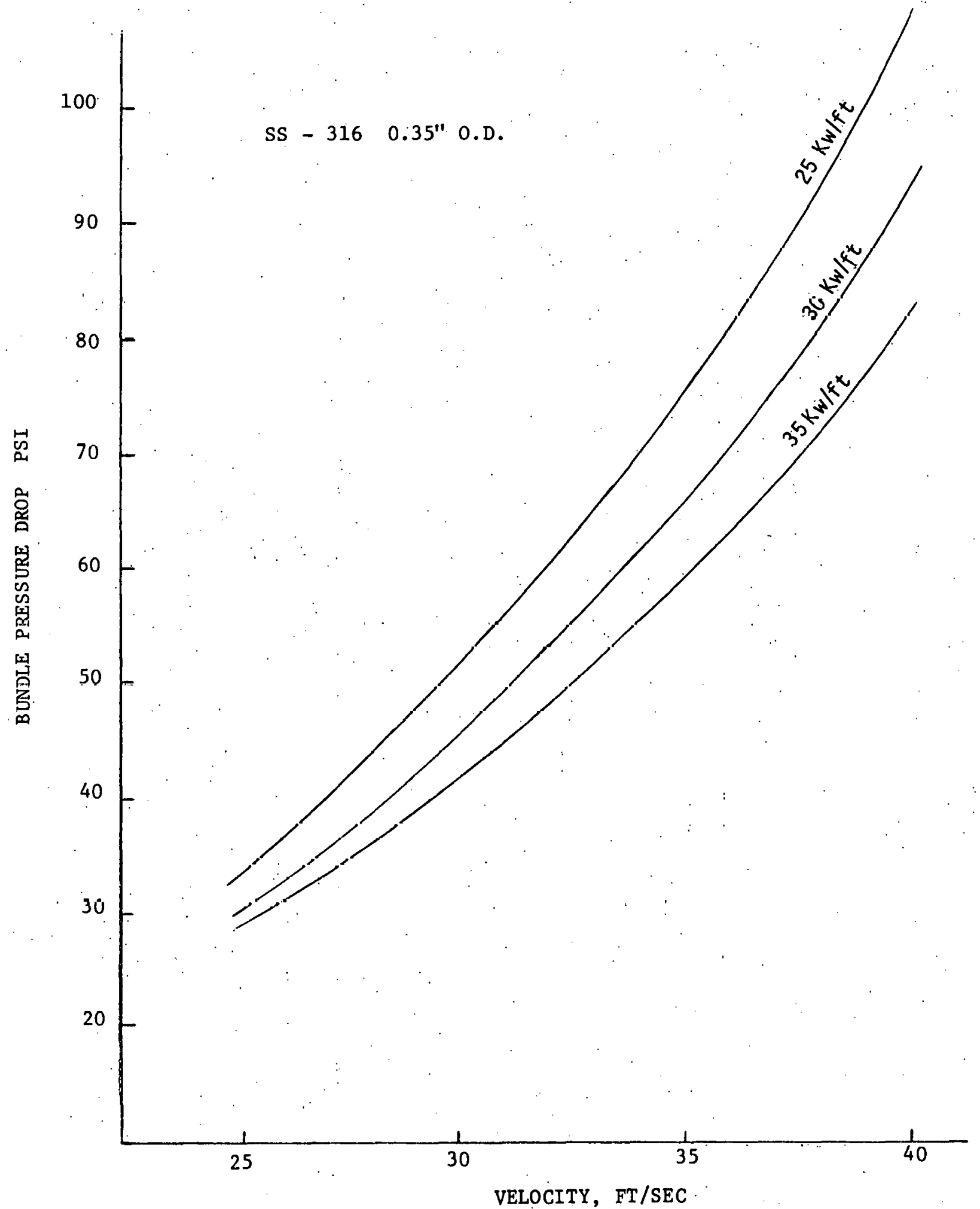

FIG. 2 EFFECT OF COOLANT VELOCITY ON BUNDLE PRESSURE GAP. 


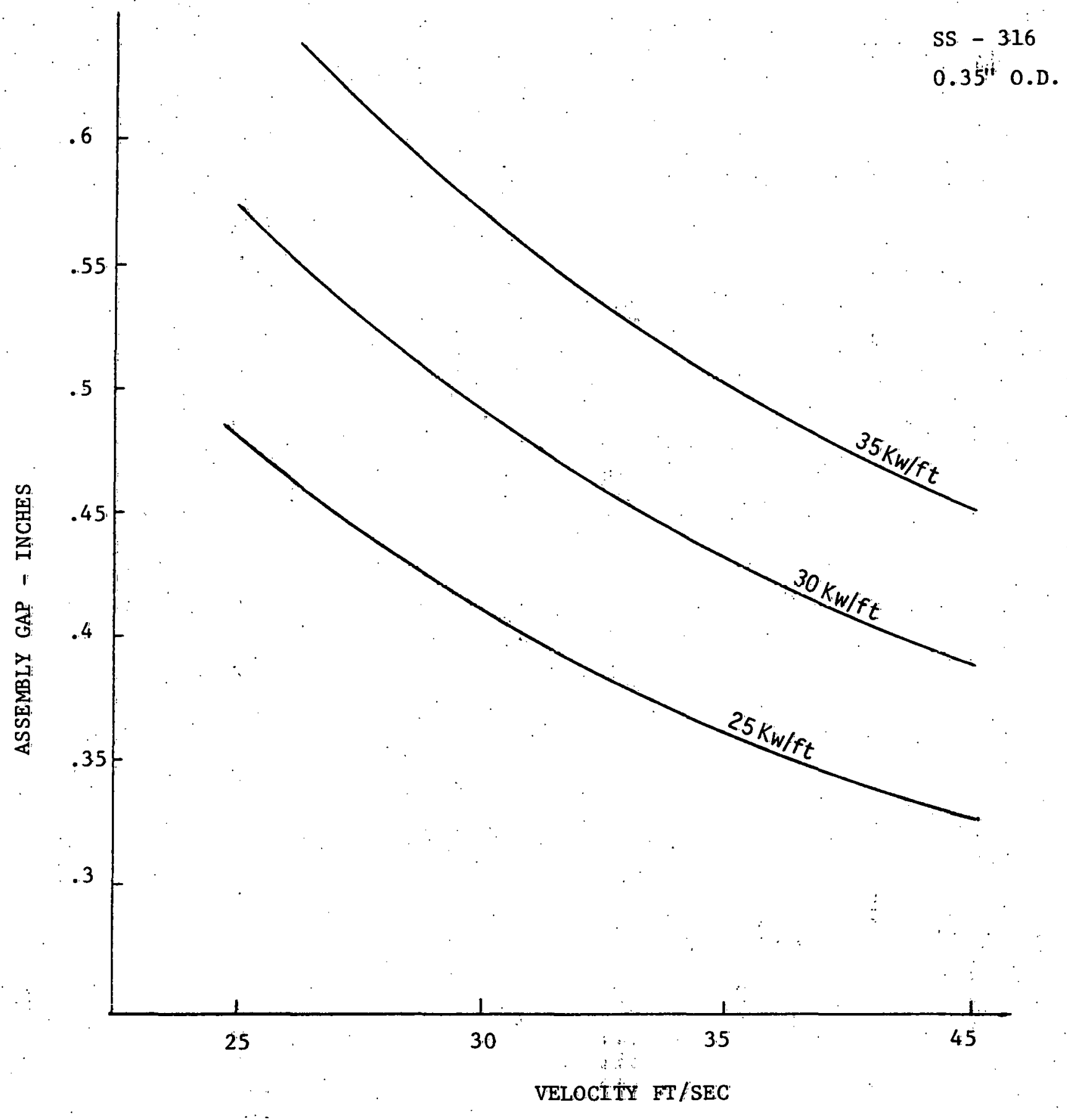

FIG. 3 EFFECT OF COOLANT VELOCITY ON INTER-ASSEMBLY GAP. 


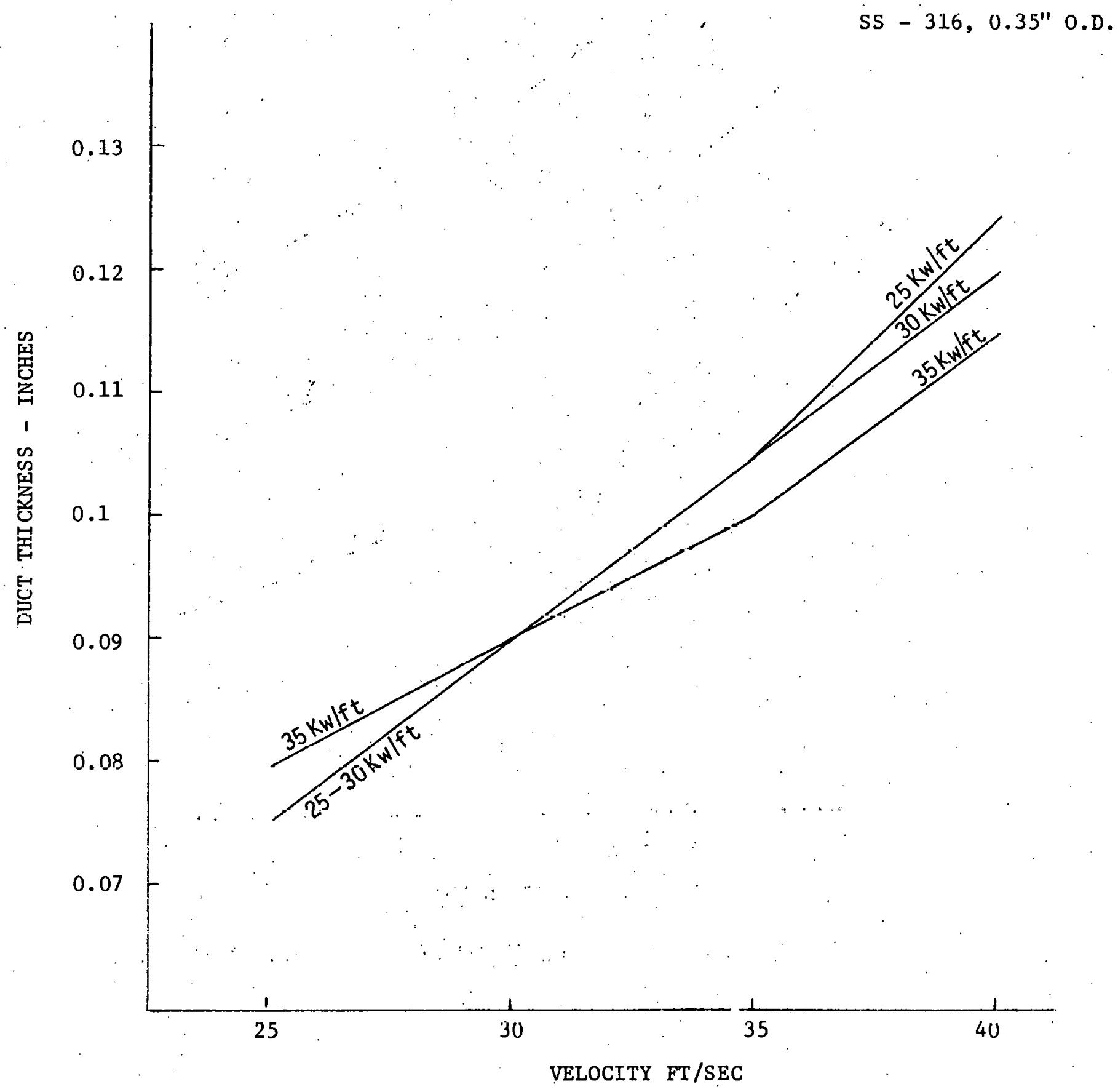

FIG. 4 EFFECT OF OUTLET TEMPERATURE ON DUCT SWELLING. 


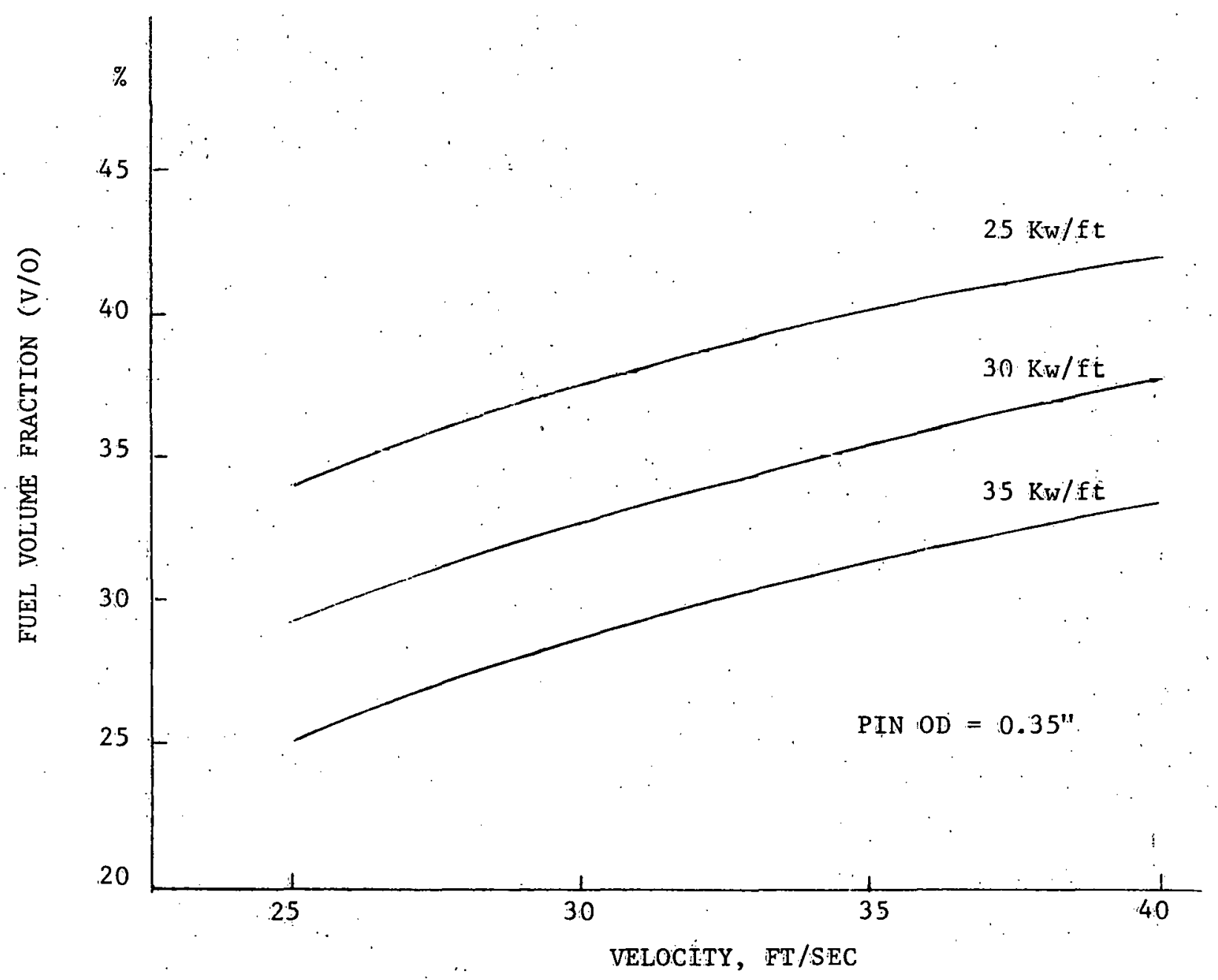

FIG. 5 THE OVERALL EFFECT OF COOLANT VELOCITY ON FUEL VOLUME FRACTION FOR $0.35^{\prime \prime}$ OD SODIUM-BOND CARBIDE PINS. 


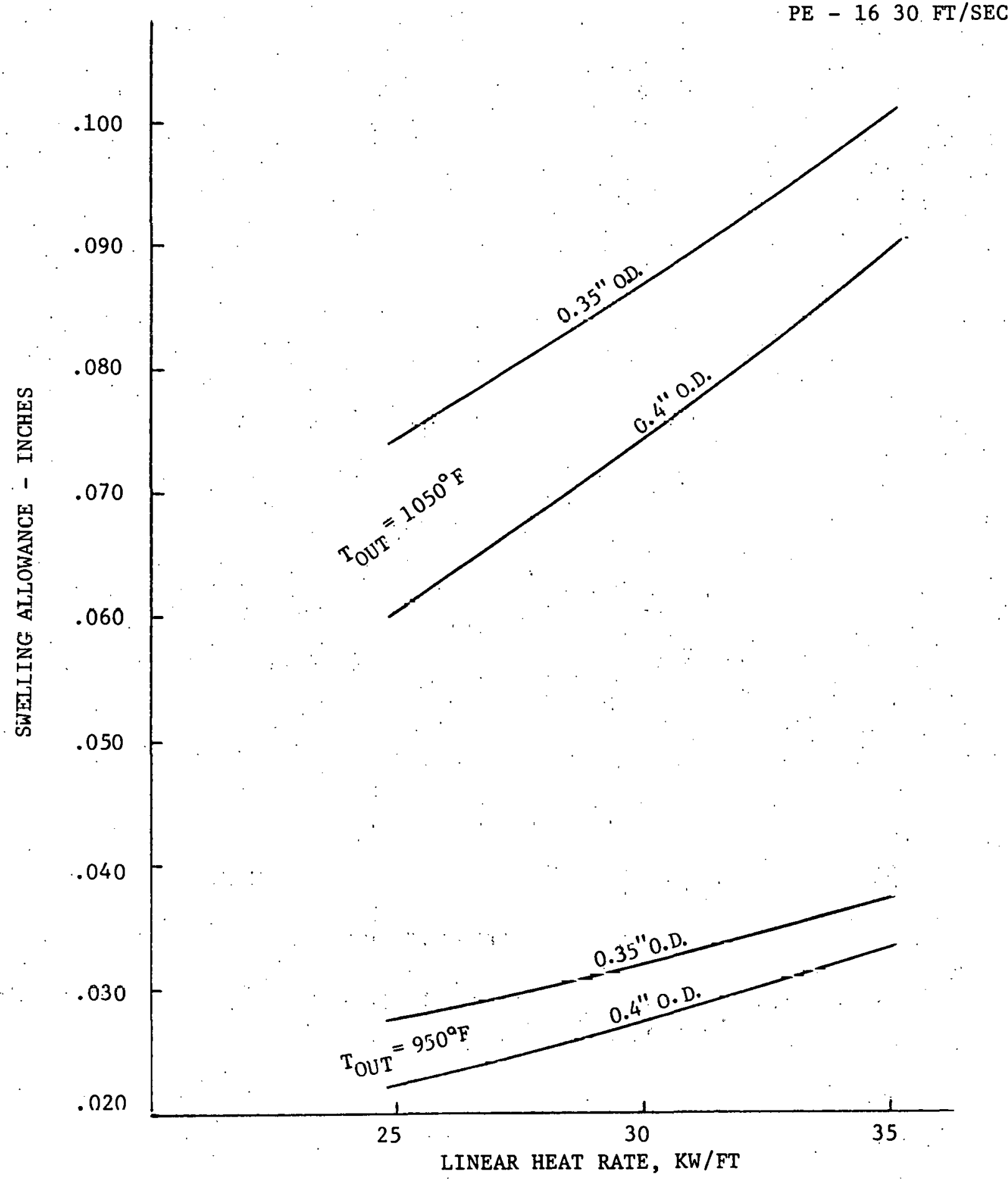

FIG. 6 BUNDLE PRESSURE DROP FOR WIRE AND GRID, 


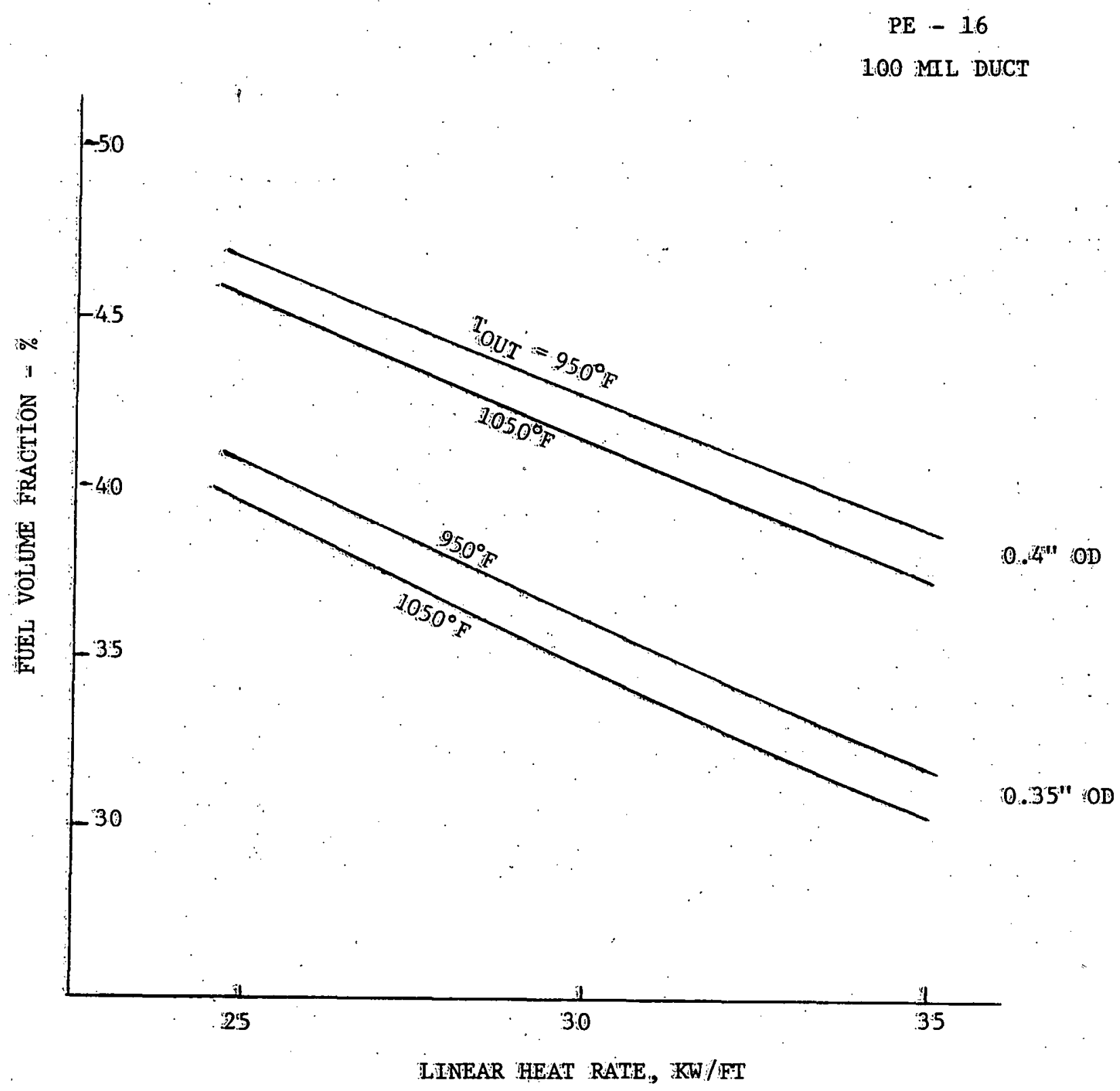

FIG. 7 EFFECT SOF CORE OUTLET TEMPERATURE ON THE FUEL WOLUME FFRACTION DUE TTO TIEMPERATURE DEPENDENCE OF DUCT SWELLING. 


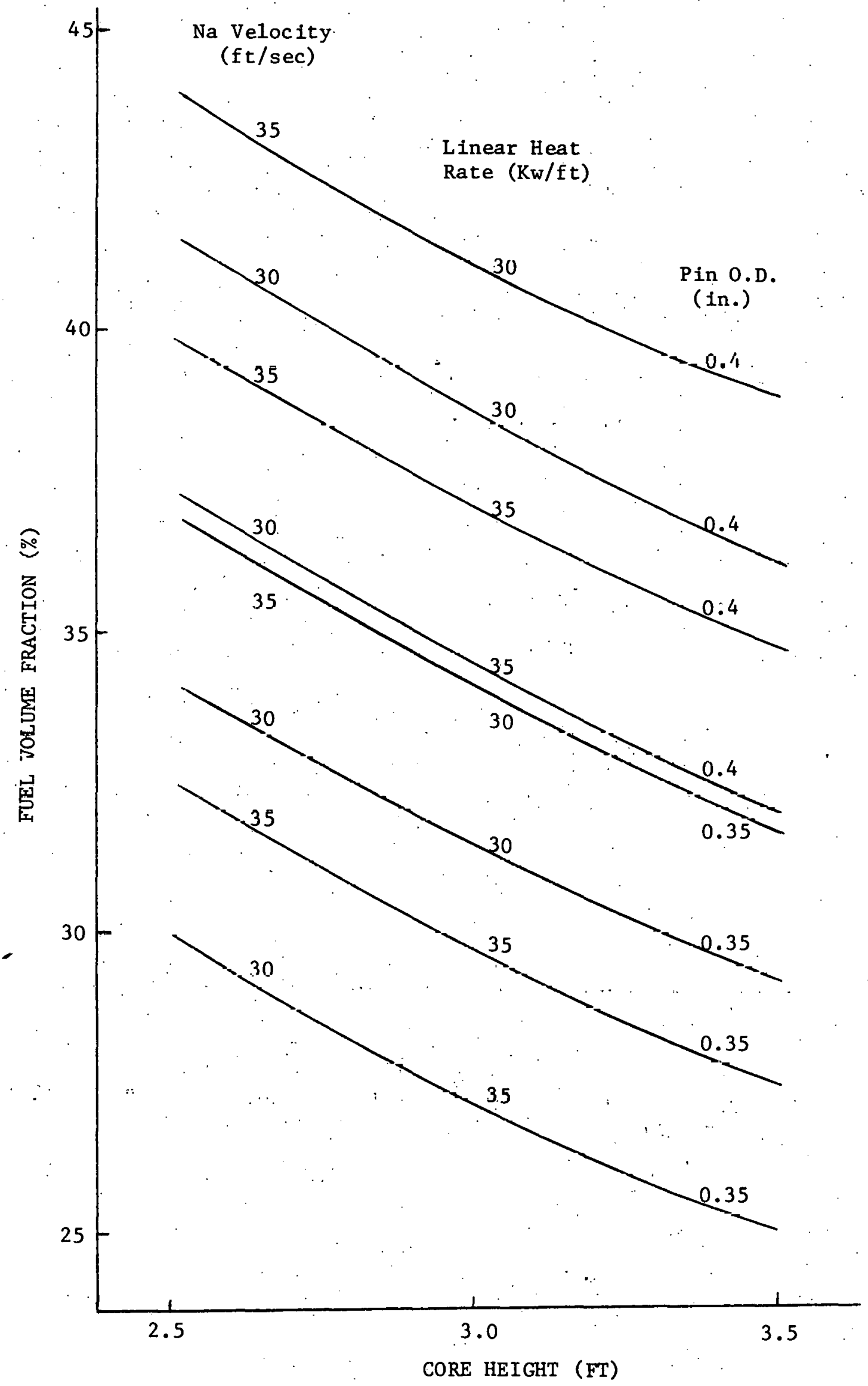

FIG. 8 EFFECT OF CORE HEIGHT ON FUEL VOLUME FRACTION. 


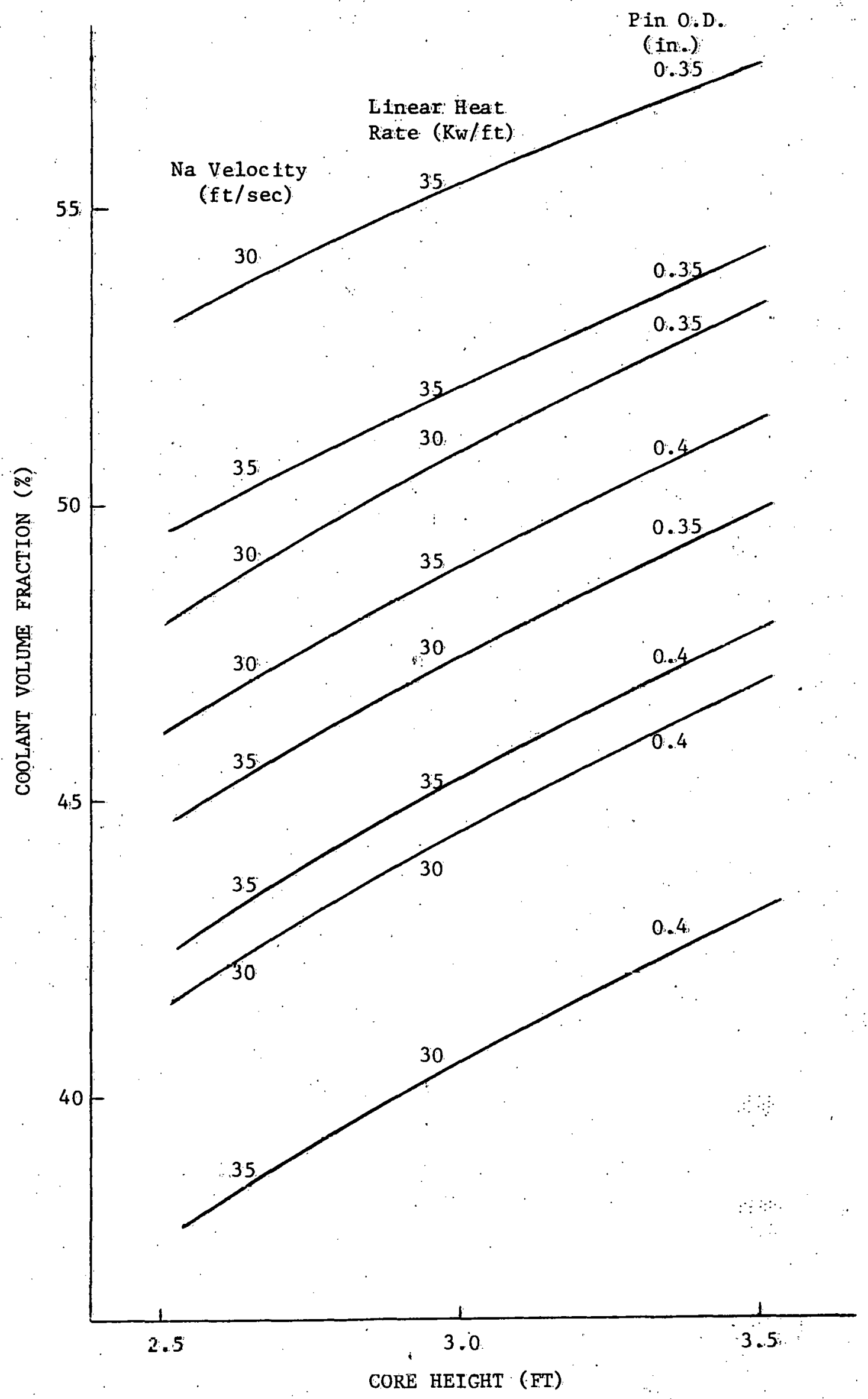

FIG. 9 EFFECT OF CORE HEIGHT ON COOLANT VOLUME FRACTION. 


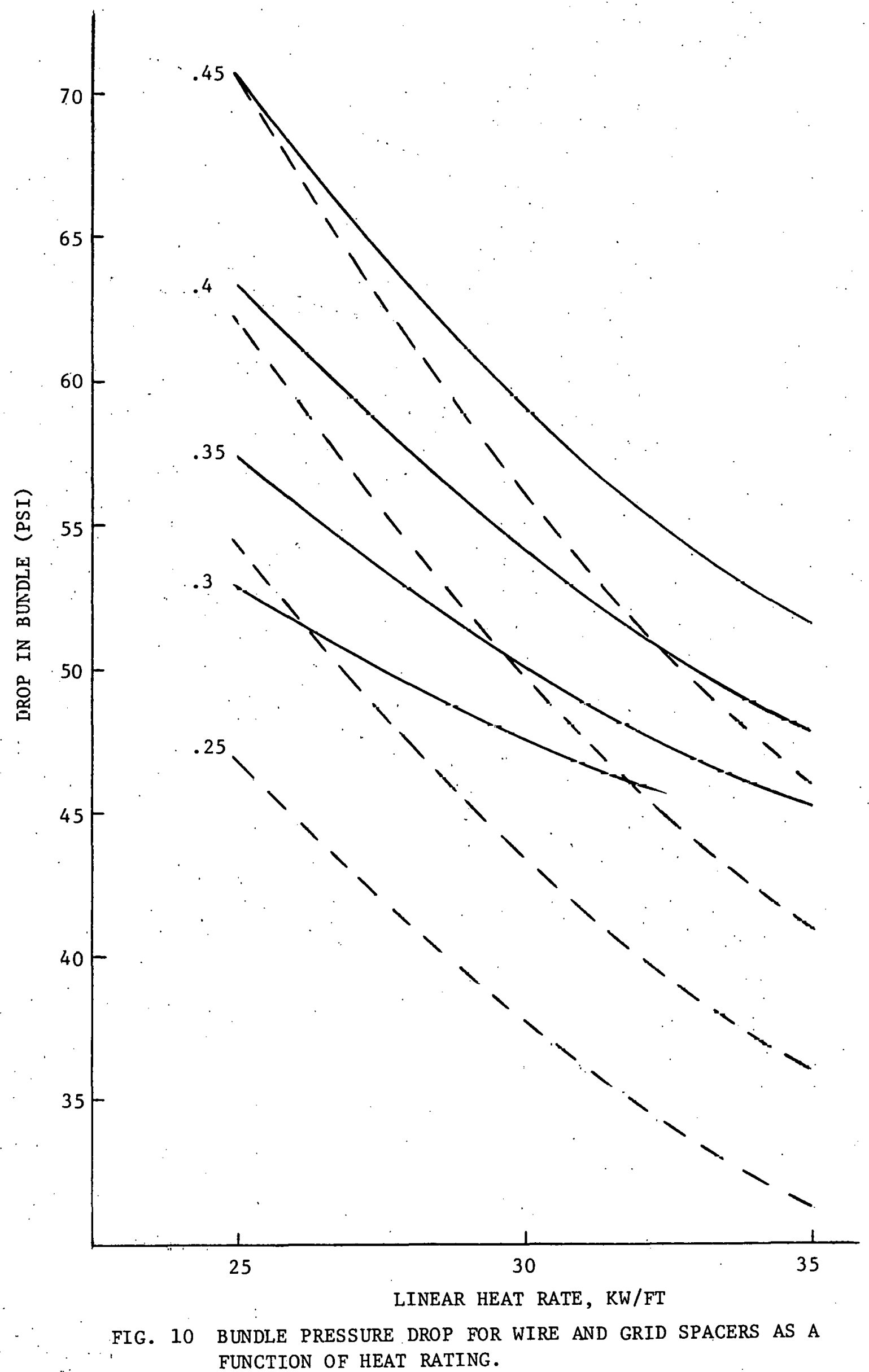




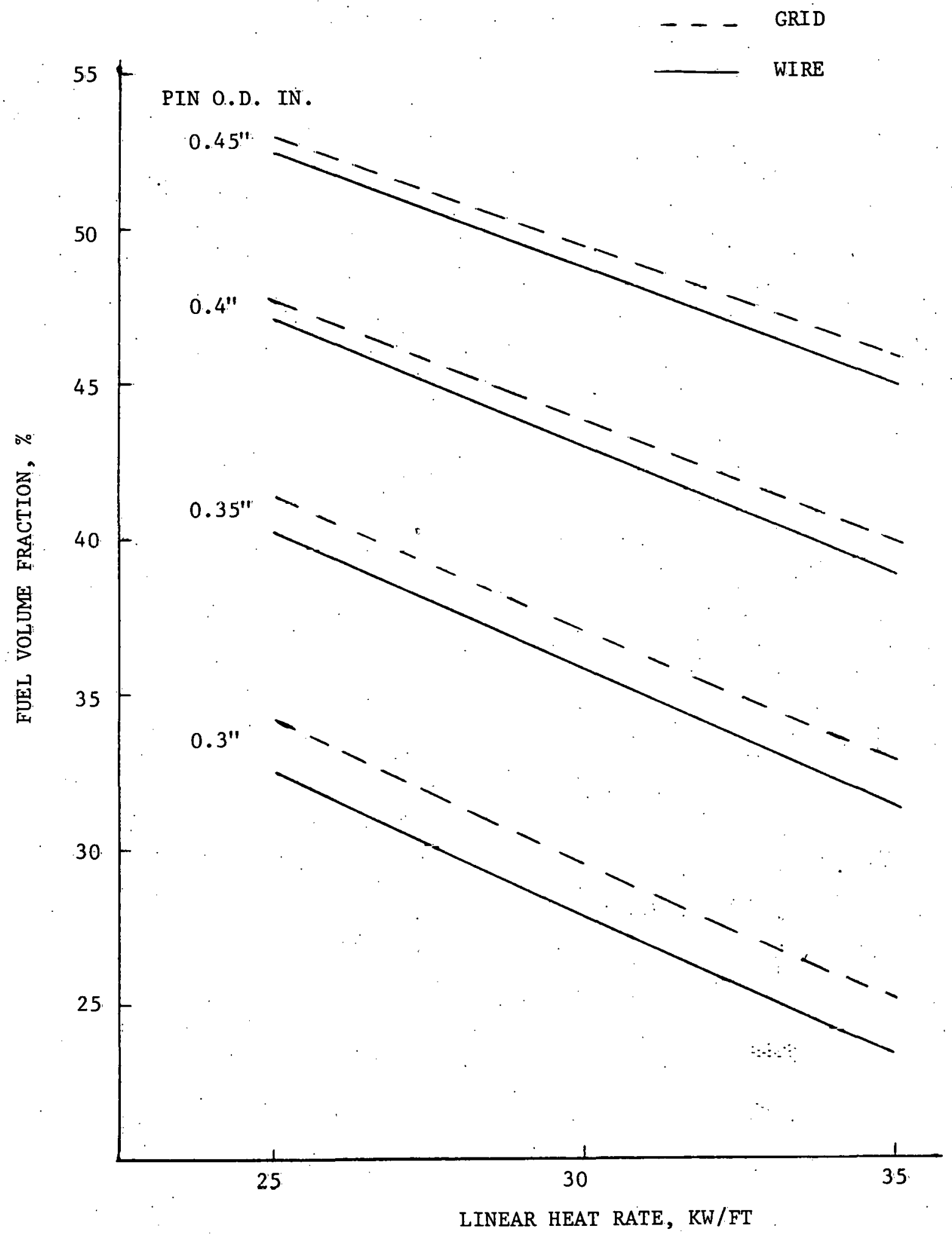

FIG. 11 FUEL VOLUME FRACTIONS FOR WIRE AND GRID-SPACED ASSEMBLIES. 


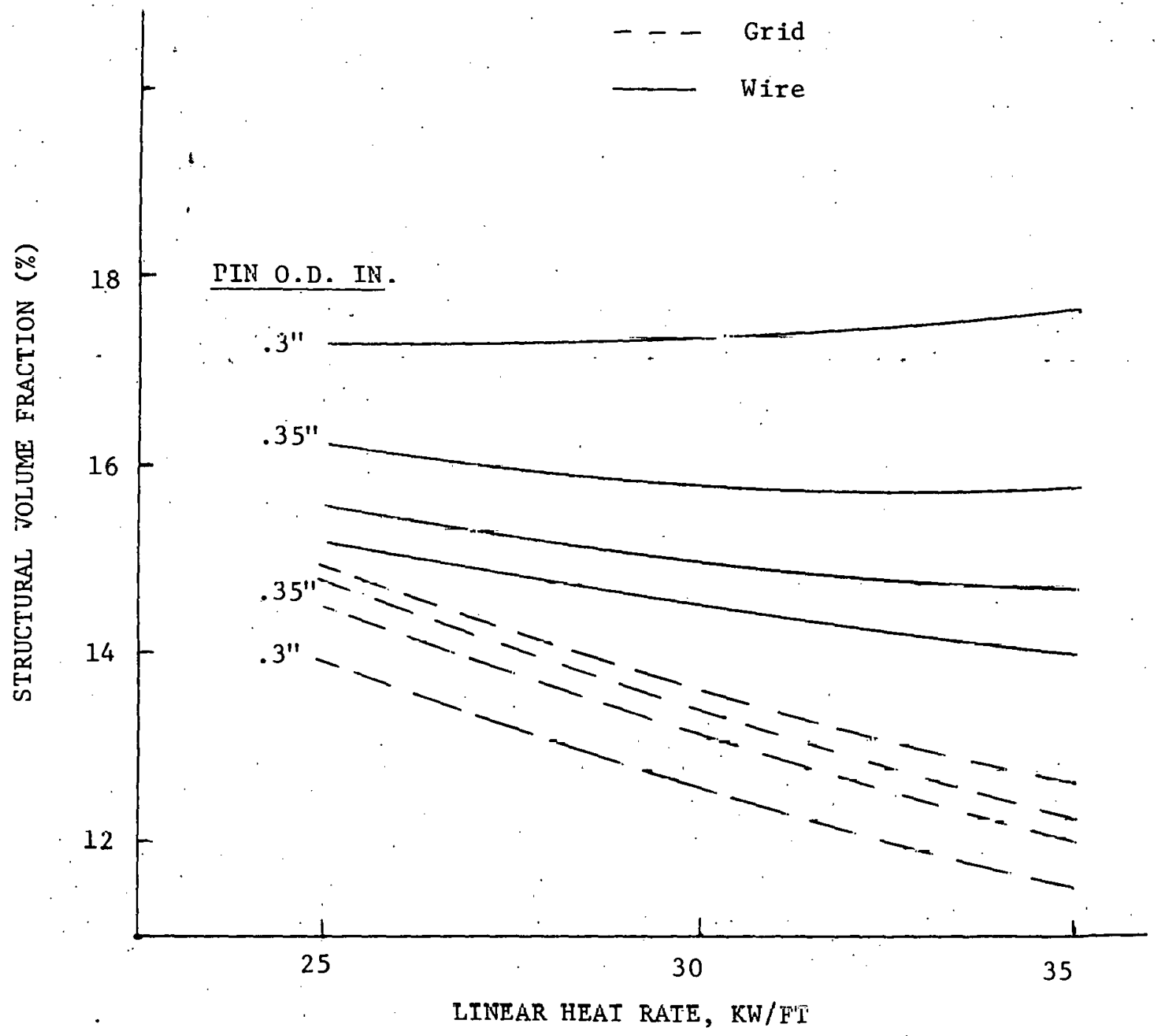

FIG. 12 STRUCTURAL VOLUME FRACTIONS FOR WIRE AND GRID-SPACED ASSEMBLIES. 


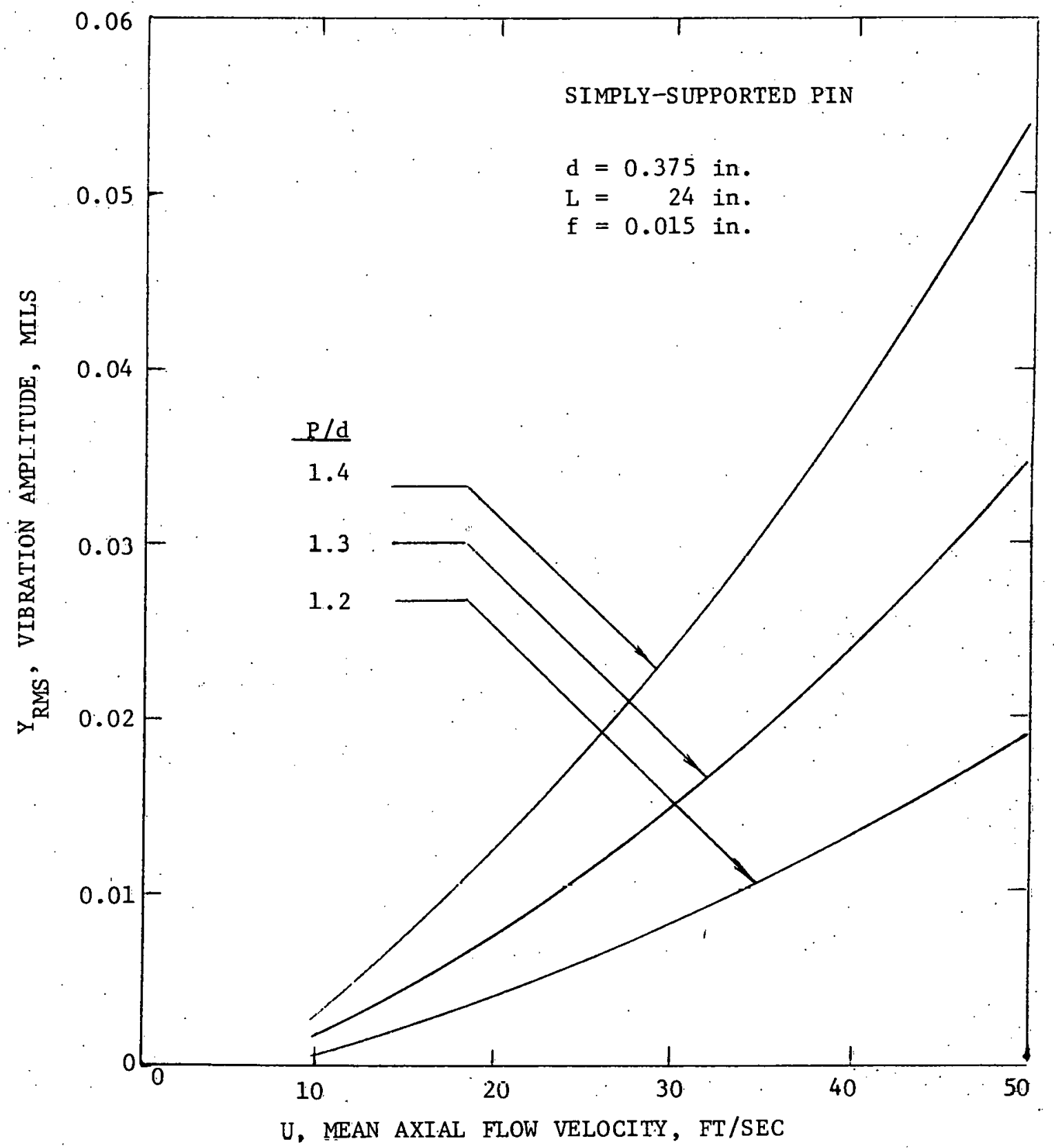

FIG. 13 VIBRATION AMPLITUDE FOR VARYING PITCH-TO-DIAMETER RATIO. 


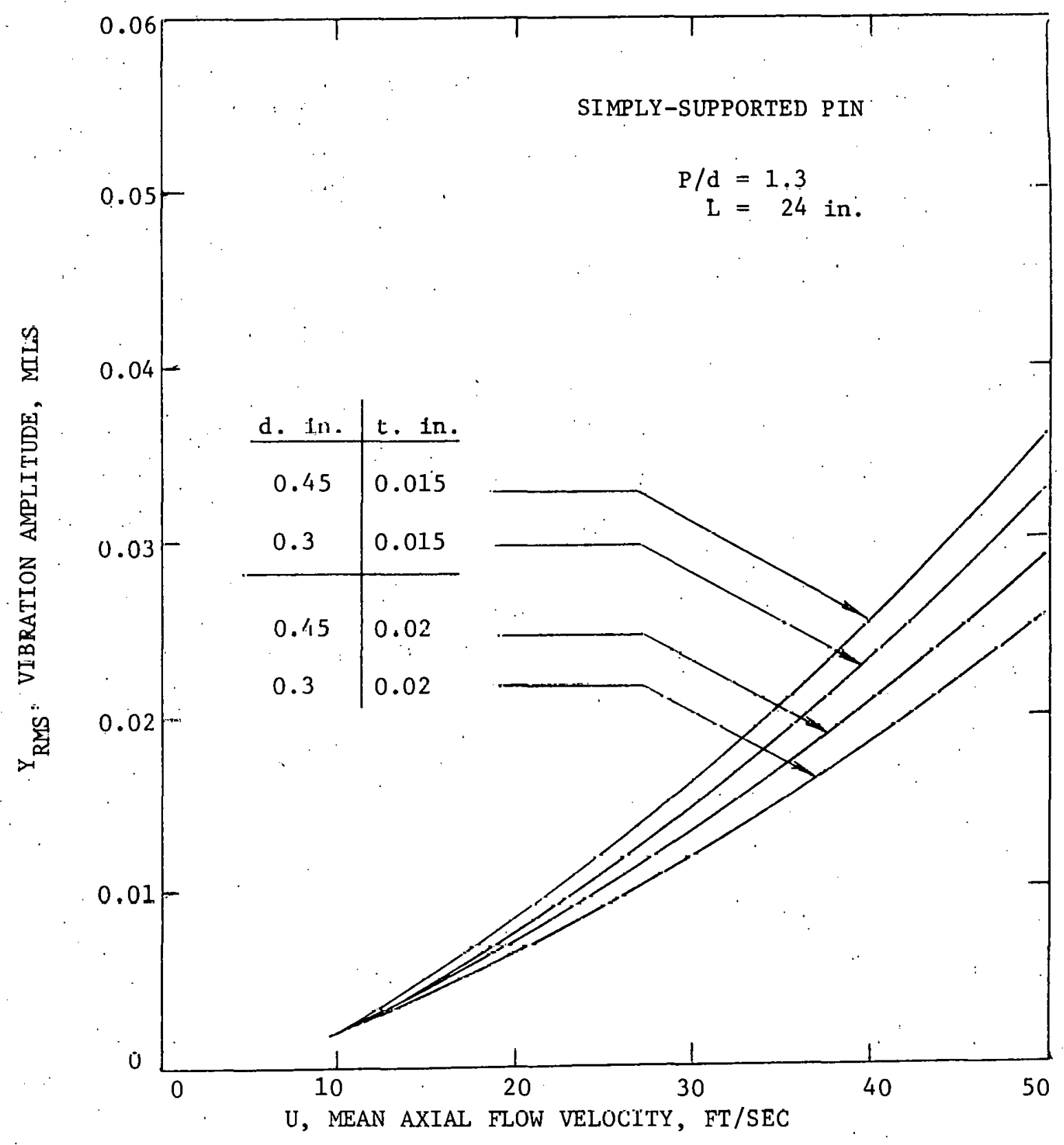

FIG. 14 EFFECT OF PIN DTAMFTER ON. VIBRATION AMPLITUDE. 


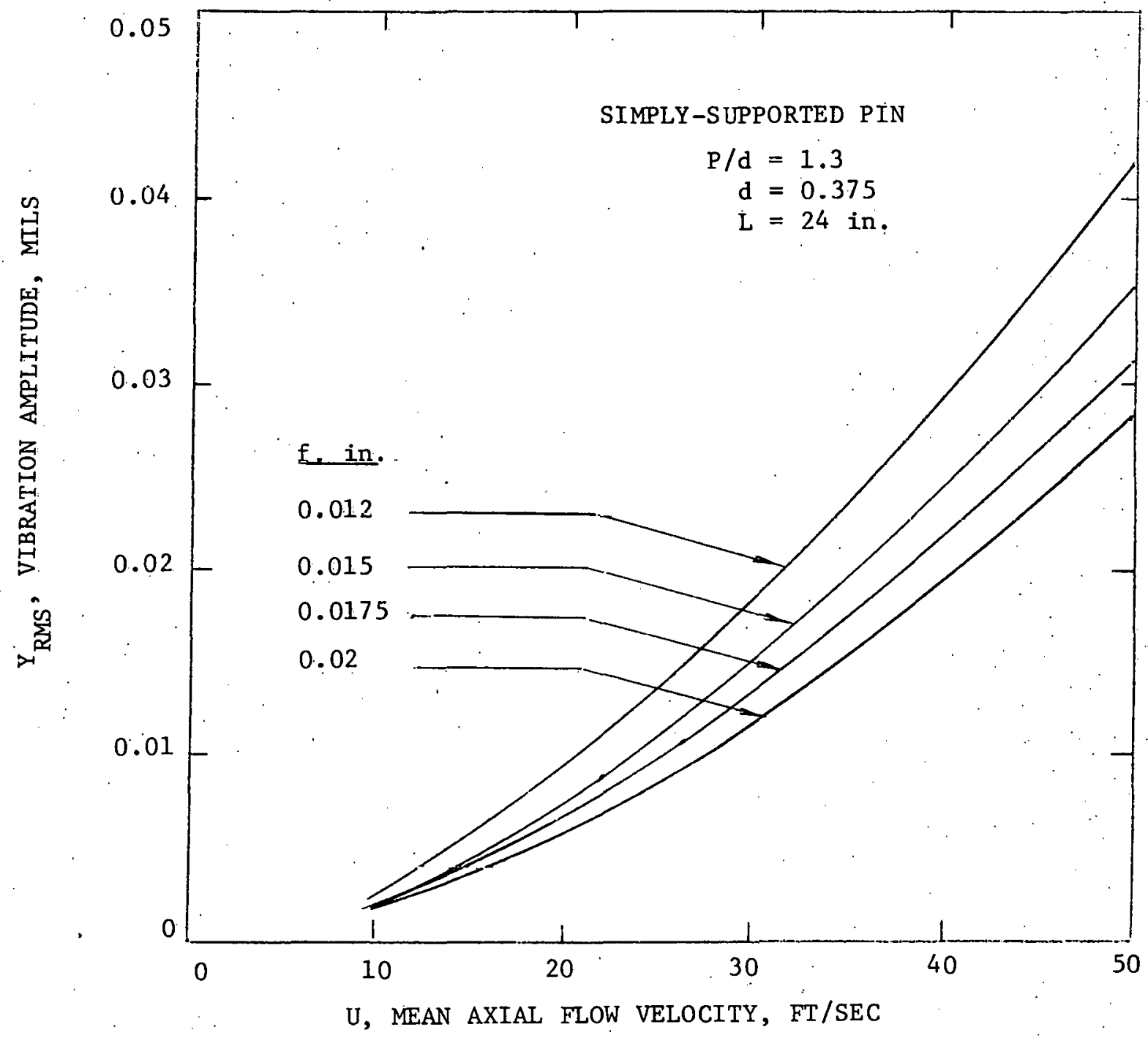

FIG. 15 EFFECT OF CLAD THICKNFSS ON VIBRATION AMPLITUDE. 


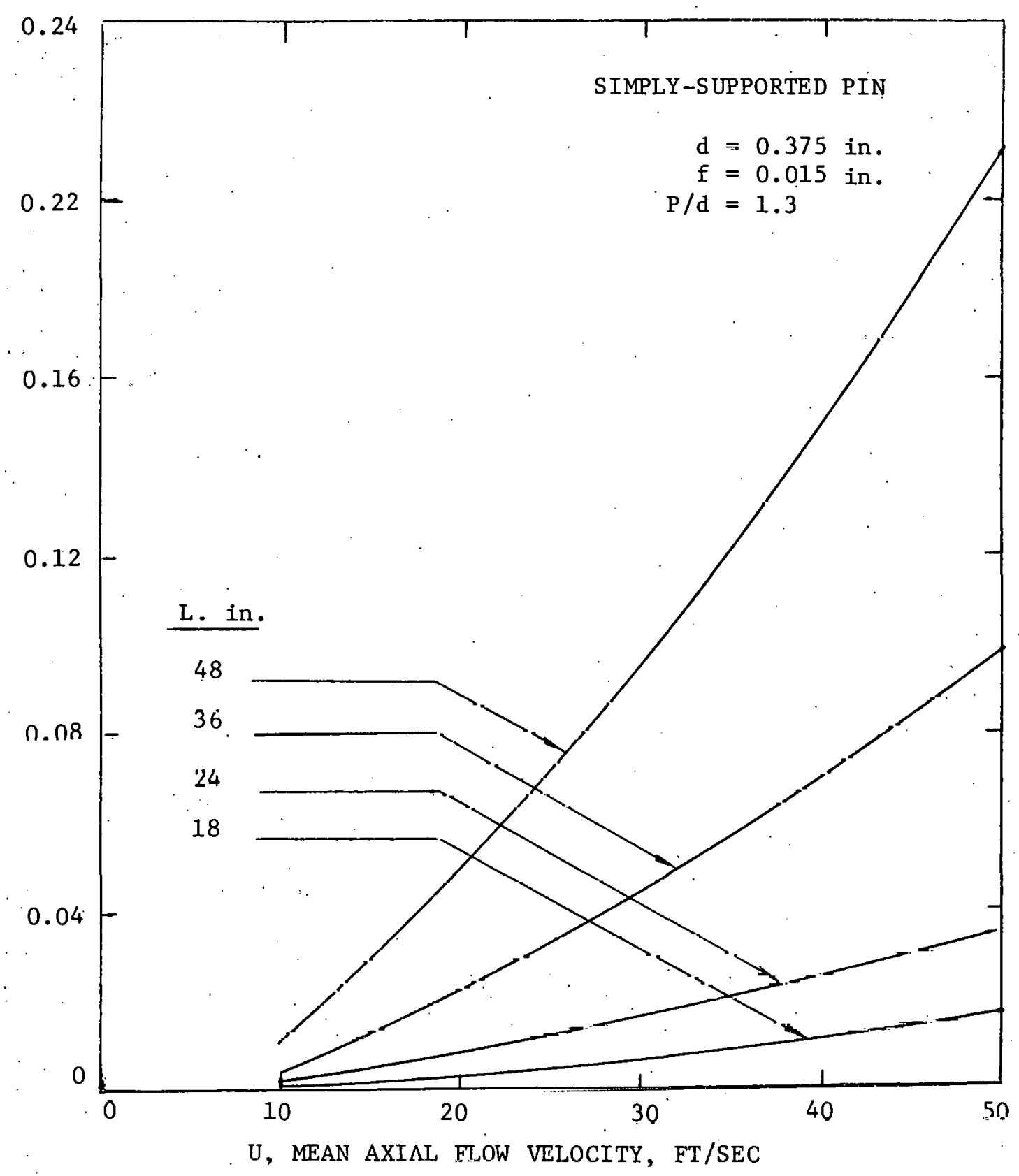

FIG. 16 EFFECT OF EQUIVALENT PIN LENGTH ON VIBRATION AMPLITUDE. 


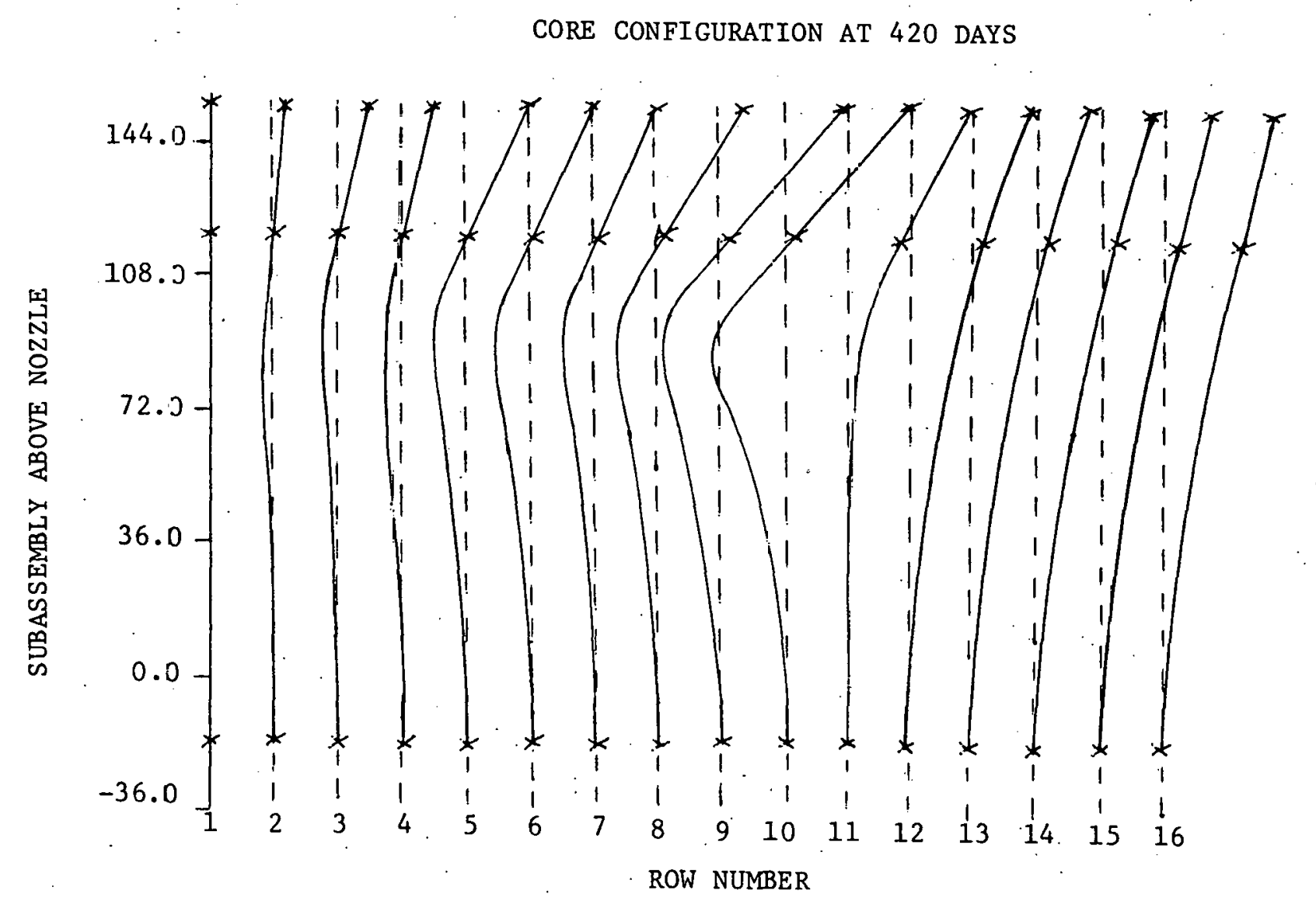

\subsection{2}

DISPLACEMENT SCALE (IN)

FIG. 17 BASE CASE - FULL PONER CONDITION 


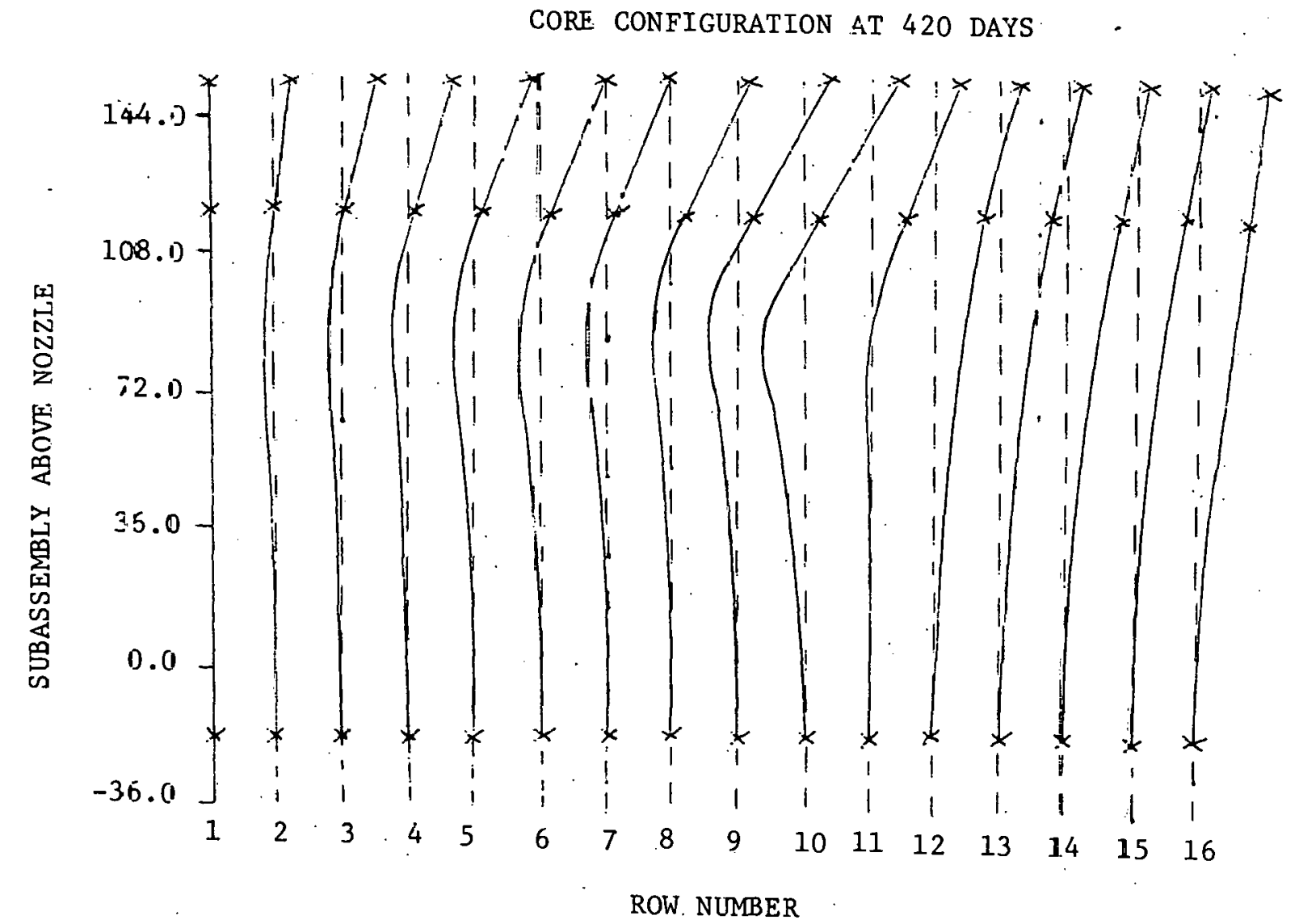

0.302

DISPLACEMENT SCALE (IN)

FIG. 18 BASE CASE WITH STIFFER DUCTS

-FULL POWER DUCTS- 